\title{
DECISION MATRIX FOR LIQUID LOADING IN GAS WELLS FOR COST/BENEFIT ANAL YSES OF LIFTING OPTIONS
}

\author{
A Thesis \\ by \\ HAN-YOUNG PARK \\ Submitted to the Office of Graduate Studies of \\ Texas A\&M University \\ in partial fulfillment of the requirements for the degree of \\ MASTER OF SCIENCE
}

May 2008

Major Subject: Petroleum Engineering 


\title{
DECISION MATRIX FOR LIQUID LOADING IN GAS WELLS FOR COST/BENEFIT ANALYSES OF LIFTING OPTIONS
}

\author{
A Thesis \\ by \\ HAN-YOUNG PARK \\ Submitted to the Office of Graduate Studies of \\ Texas A\&M University \\ in partial fulfillment of the requirements for the degree of \\ MASTER OF SCIENCE
}

\begin{abstract}
Approved by:
Chair of Committee, Gioia Falcone

Committee Members, Catalin Teodoriu

Marietta J. Tretter

Head of Department, Stephen A. Holditch
\end{abstract}

May 2008

Major Subject: Petroleum Engineering 


\begin{abstract}
Decision Matrix for Liquid Loading in Gas Wells for Cost/Benefit Analyses of Lifting Options. (May 2008)

Han-Young Park, B.S., Hanyang University, Seoul

Chair of Advisory Committee: Dr. Gioia Falcone
\end{abstract}

Field-proven solutions already exist to reduce the loss of gas production when liquid loading begins to occur. However, the choice of remedial technique, its feasibility, and its cost, vary considerably depending on a field's location, size export route, and the individual operator's experience. The selection of the best remedial technique and the timeframe within which the remedial action is undertaken are critical to a project's profitability. Although there are literature reviews available regarding solutions to liquid loading problems in gas wells, a tool capable of helping an operator select the best remedial option for a specific field case still does not exist.

This thesis proposes a newly developed decision matrix to screen the possible remedial options available to the operator. The matrix can not only provide a critical evaluation of potential solutions to the problem of liquid loading in gas wells vis-à-vis the existing technical and economic constraints, but can also serve as a reference to operators for investment decisions and as a quick screening tool for the selection of production optimisation strategies. 
Under its current status of development, this new tool consists of a decision algorithm built around a decision tree. Unlike other data mining techniques, decision trees quickly allow for subdividing large initial datasets into successively smaller sets by a series of decision rules. The rules are based on information available in the public domain. The effectiveness of the matrix is now ready to be tested against real field datasets. 


\section{DEDICATION}

TO MY WIFE AND DAUGHTER 


\section{ACKNOWLEDGEMENTS}

First of all, I would like to express my sincere gratitude and appreciation to my advisor, Dr. Gioia Falcone for her invaluable guidance, encouragement, and continuous technical advice in completing this work.

I am extremely grateful to Dr. Catalin Teodoriu and Dr. Marietta J. Tretter who served as members of my committee for helping me throughout the completion of my study.

I would also like to thank all my officemates and classmates for their friendship and my thanks go to Texas A\&M University for the quality education that I have received and for being the home that I will never forget.

Finally, I thank God for empowering and guiding me during the course of my Master of Science degree. 


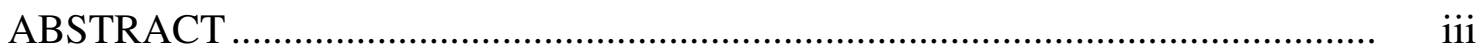

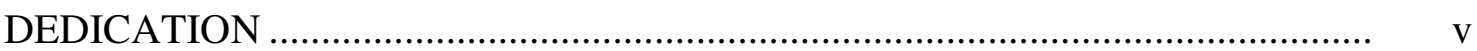

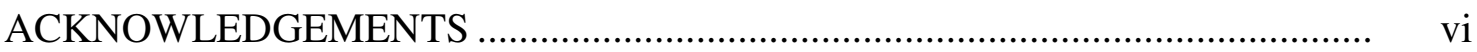

TABLE OF CONTENTS .................................................................... vii

LIST OF FIGURES ........................................................................................ ix

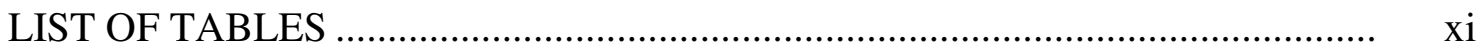

CHAPTER

I IMPORTANCE OF THIS RESEARCH.................................................

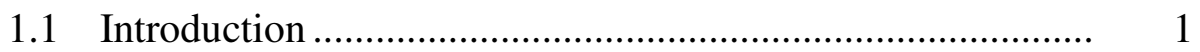

1.2 Objectives...................................................................... 2

II LITERATURE REVIEW ……………………………………...........

2.1 Liquid Loading in Gas Wells ................................................ 3

2.2 Remedial Options to Reduce Liquid Loading Problems....... 7

2.3 Current Development Status on Prediction of Liquid Loading and Selection of Remedial Options ........................ 20

2.4 Limiation of Previous Attemps to Select Remedial Options ……................................................................ 25

III METHODOLOGY AND APPROACH TO DECISION MATRIX ........... 26

3.1 Possible Approaches: Data Mining Techniques.................... 26

3.2 Approach Chosen for This Work …………………............... 34

3.3 Consideration Factors in Selection of Techniques ................ 35

IV DEVELOPMENT OF DECISION MATRIX............................................ 41 
CHAPTER Page

$4.1 \quad$ Introduction ................................................................. 41

4.2 Decision Tree \& Preliminary Screening [Round 1] ............. 43

4.3 Technical Evaluation of Lifting Options [Round 2] ............ 57

4.4 Economic Evaluation of Lifting Options [Round 3]............ 59

4.5 Decision Matrix Programming............................................ 61

4.6 Field Data to Validate Decision Matrix ............................ 71

V CONCLUSION AND RECOMMENDATION FOR FUTURE WORK .... 73

5.1 Conclusion..................................................................... 73

5.2 Recommendation for Future Work .................................... 74

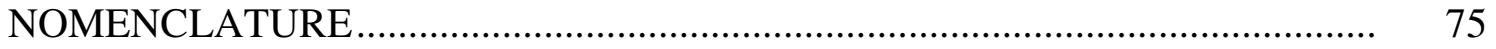

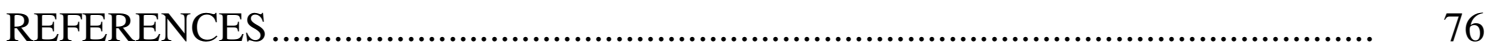

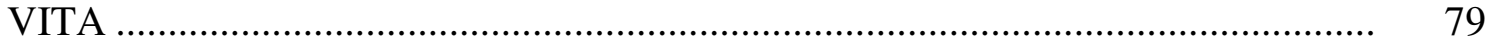




\section{LIST OF FIGURES}

FIGURE

Page

2.1 Flow regimes in vertical multiphase flow..........................................................

2.2 Progression of a typical gas well. ................................................................

2.3 Decline curve showing onset of liquid loading ............................................... 6

$2.4 \quad$ Map of deliquification options. .....................................................................

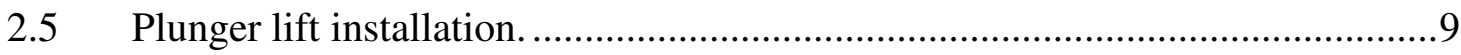

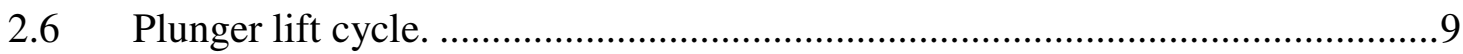

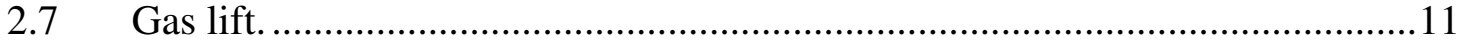

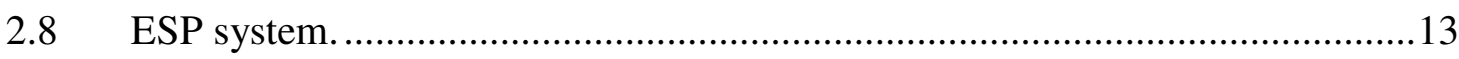

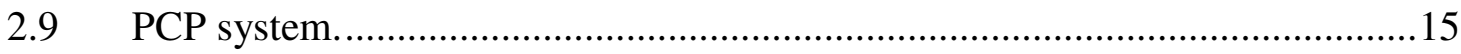

$2.10 \quad$ Sucker rod pump system. ............................................................................16

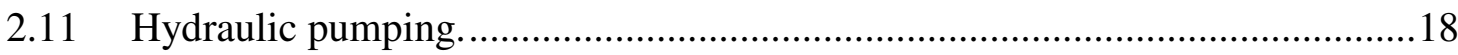

2.12 Well performance model for gas wells with liquid loading problem................22

2.13 Multi-criteria model. .................................................................................. 24

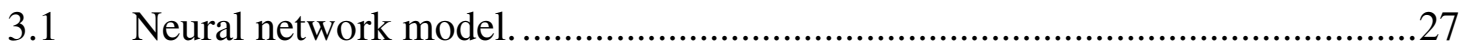

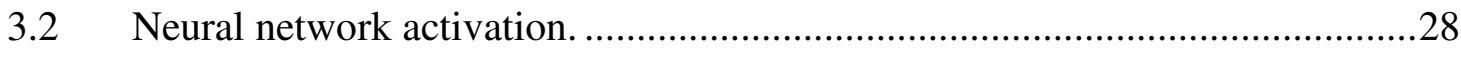

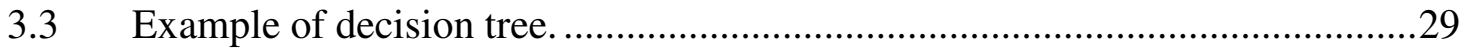

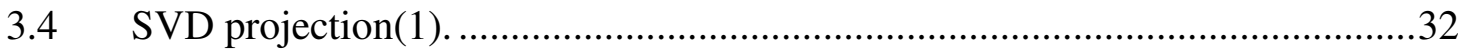

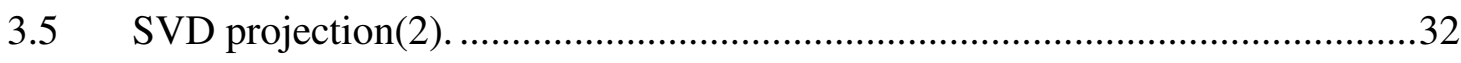

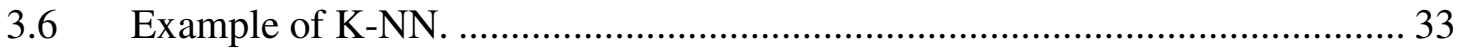

4.1 Work flow and possible approaches to data mining. .........................................41

4.2 General structure of decision matrix............................................................. 43

4.3 Developed decision tree to screen remedial options..........................................45

4.4 Applicability of technical remedial options by well deviation. ..........................48

4.5 Applicability of technical remedial options by well depth. ...............................49

4.6 Applicability of technical remedial options by operating volume. .....................50 
FIGURE $\quad$ Page

4.7 Approximate depth-rate application chart of technical remedial options. ........51

4.8 Feasibility of plunger lift for $23 / 8$ inch tubing and $27 / 8$ inch tubing...............52

4.9 GLR requirement for plunger lift with/without packer................................53

4.10 Applicability of technical remedial options by gravity …..............................54

4.11 Programmed decision matrix - Round 1 (1) ............................................62

4.12 Programmed decision matrix - Round 1 (2) .............................................63

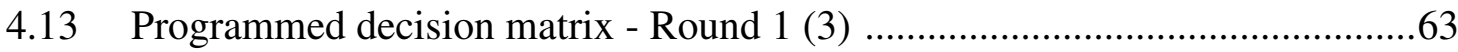

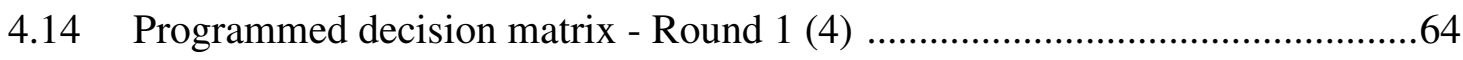

4.15 Programmed decision matrix - Round 1 (5) ........................................64

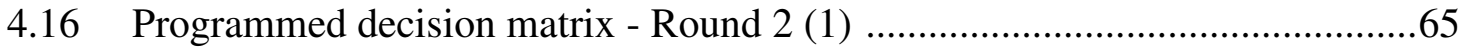

4.17 Programmed decision matrix - Round 2 (2) .............................................66

4.18 Programmed decision matrix - Round 3 .............................................67

4.19 Programmed decision matrix - Comprehensive review (1) ….......................68

4.20 Programmed decision matrix - Comprehensive review (2) .........................69

4.21 Programmed decision matrix - Comprehensive review (3) ............................70 


\section{LIST OF TABLES}

TABLE

Page

2.1 Remedial Measures to Reduce Liquid Loading ........................................... 7

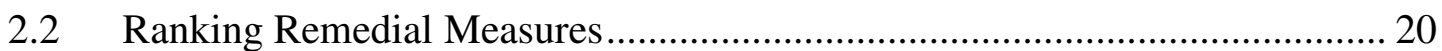

4.1 Power Source of Artificial Lift Methods..................................................... 55

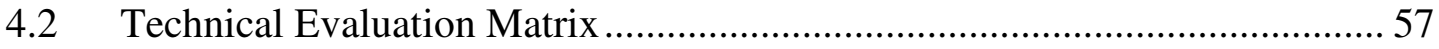




\section{CHAPTER I}

\section{IMPORTANCE OF THIS RESEARCH}

\section{$1.1 \quad$ Introduction}

Liquid loading is an all too common problem in mature gas fields. It is estimated that at least $90 \%$ of the producing gas wells in the U.S. are operating in liquid loading regime. Liquid loading is more detrimental in tight wells than in prolific wells, where it has less impact. The phenomenon is a serious problem in subsea tie-backs, where the mechanics of fluid flow are dominated by back pressure effects through the risers and the flowlines.

Although the mechanism of liquid loading is fairly well understood, the oil and gas industry still lacks reliable predictive models.

Efforts are being made across the industry and within academia to link the observed well dynamics with the intermittent response of a reservoir that is typical of liquid loading in gas wells. However, the models currently used to predict and diagnose liquid loading problems are mainly based on steady-state analysis and so cannot handle the transient phenomena associated with liquid loading effects. Even when transient multiphase wellbore models are employed, the problem remains ill-posed as a steadystate type of inflow performance relationship is being used to characterize the reservoir. This implies the wrong boundary conditions between the well and the reservoir itself.

This thesis follows the publication style of SPE Journal. 
Field-proven solutions already exist to reduce the loss of gas production when liquid loading begins to occur. However, the choice of remedial technique, its feasibility, and its cost vary dependent on the affected field's location, its size, and its export route.

Given the limited applicability of current multiphase models and the paucity of published field cases, we propose to approach the problem by gathering and synthesizing field data from key regions worldwide that show different liquid loading characteristics and present different technical and economical challenges.

\subsection{Objectives}

The objective of this research is to build a generic decision matrix, based on data, to screen the possible remedial options available to the operator; in addition, the impact of over-designing and under-designing the production facilities will be evaluated and quantified from a cost/benefit analysis point of view. The matrix will be designed to forecast what profitability may result, either in increased gas sales, increased reserves, or both. The remedial options will include accepted practices and up and coming techniques.

Among the various approaches that will be taken to build the decision matrix is the use of what is referred to as a decision tree in data mining techniques. This is a wellknown technique, particularly effective for classification problems, and it is easy to understand and interpret. 


\section{CHAPTER II}

\section{LITERATURE REVIEW}

\subsection{Liquid Loading in Gas Wells}

\subsubsection{Flow Patterns in a Gas Well}

The flow pattern in a vertical production conduit of a gas well is usually illustrated by four basic flow patterns or flow regimes as shown in Fig. 2.1. The flow regimes are largely classified with bubble flow, slug flow, slug-annular transition flow and annularmist flow, which are determined by the velocity of the gas and liquid phases and the relative amounts of gas and liquid at any given point in the flow stream.

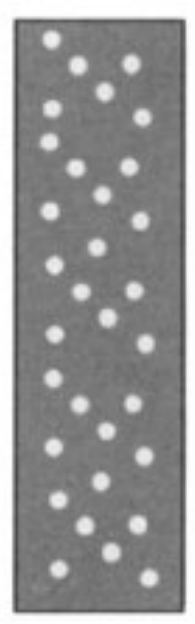

Bubble

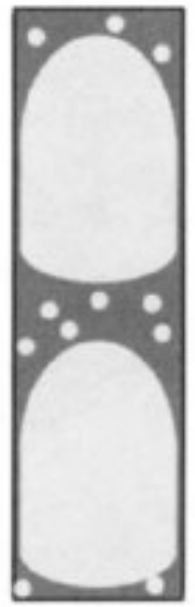

Slug

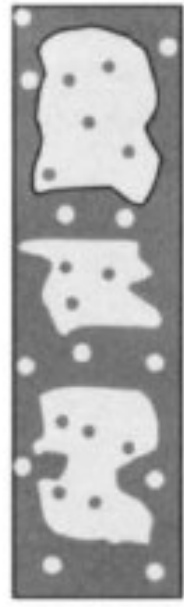

Slug-annular transition

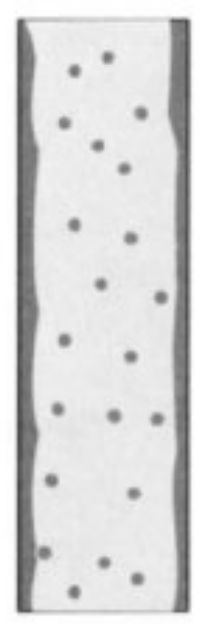

Annular-mist Increasing gas rate

Fig. 2.1 - Flow regimes in vertical multiphase flow (Lea, 2003). 
If the flow pattern is an annular-mist type, the well still may have a relatively low gravity pressure drop. However, as the gas velocity begins to drop, the well flow can become a slug type and then bubble flow. In these cases, a much larger fraction of the tubing volume is filled with liquid.

A gas well may go through any or all of these flow regimes during its lifetime. The general progression of a typical gas well from initial production to its end of life is shown in Fig. 2.2.

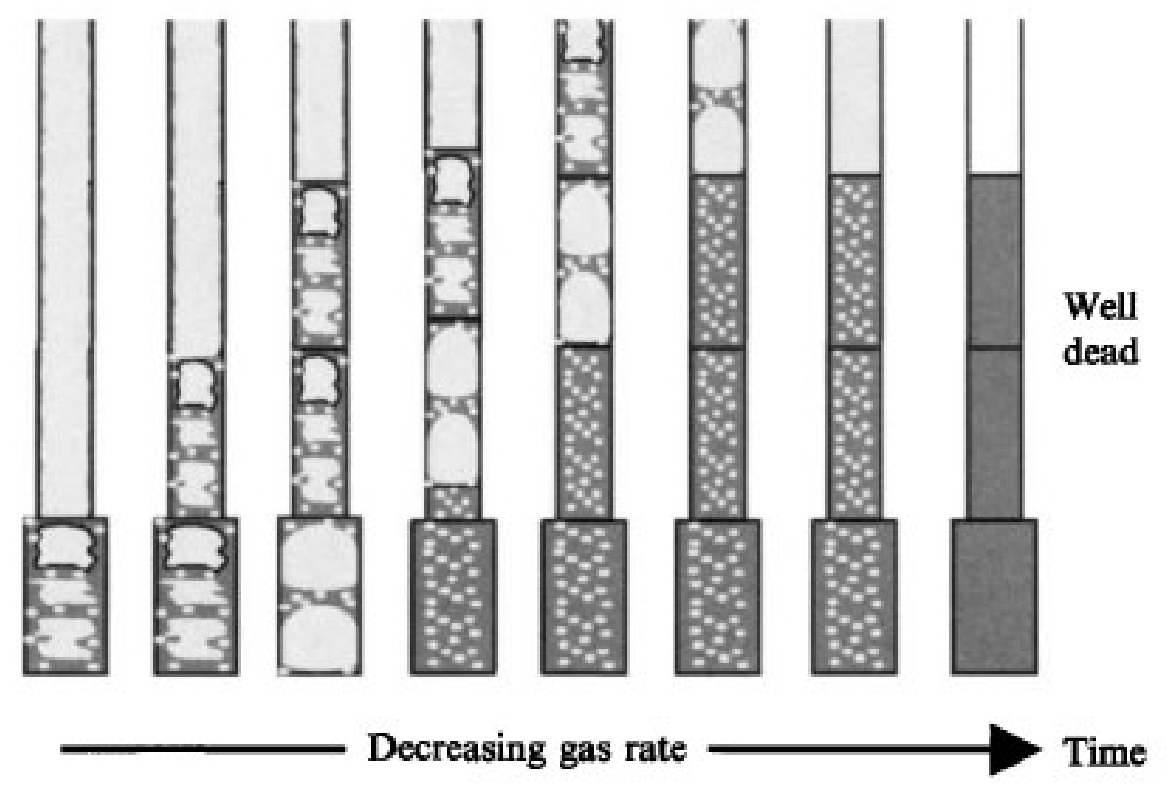

Fig. 2.2 - Progression of a typical gas well (Lea, 2003).

Initially, the well may show the mist flow regime that brings a high gas rate and then transit into slug-annular transition, slug, and bubble flow with time. Liquid production may also increase as the gas production declines. Flow at the surface will remain in mist 
flow until the conditions change sufficiently at the surface so that the flow exhibits transition flow. Flow downhole may show bubble or slug flow even though the flow regime at the surface looks like a mist flow.

\subsubsection{Occurrence of Liquid Loading}

Gas and liquid are both produced to surface if the gas velocity is high enough to lift or carry liquid. The problem happens because the velocity of the gas in the tubing drops with time, and the velocity of the liquids decline even faster as the production goes on. As a result, the liquid begins to accumulate in the bottom of the well and liquid slugs are formed in the conduit, which increase the percentage of liquids in the conduits while the well is flowing. The bottomhole pressure increases and gas production decreases until gas flow stops. In other words, the liquid loading process occurs when the gas velocity within the well drops below a certain critical gas velocity. The gas is then unable to lift the water coproduced with the gas (either condensed or formation water) to surface. The water will fall back and accumulate downhole. A hydrostatic column is formed that imposes a back pressure on the reservoir and hence reduces gas production. The process eventually results in intermittent gas production and well die-out.

Several sources may be suspected as the source of liquid causing the problem. It is reasonably said that the liquid sources may be from water coning, aquifer water, water produced from another zone, free formation water, and hydrocarbon condensate. 


\subsubsection{Recognizing of Symptoms of Liquid Loading}

The occurrence of liquid loading in a gas well can be recognized by several symptoms. If it is found out early and then the appropriate action is taken at a proper time, the losses in gas production can be minimized. The symptoms indicating liquid loading summarized by James F. Lea (2004) are like following:

- Sharp reduction of flow rate

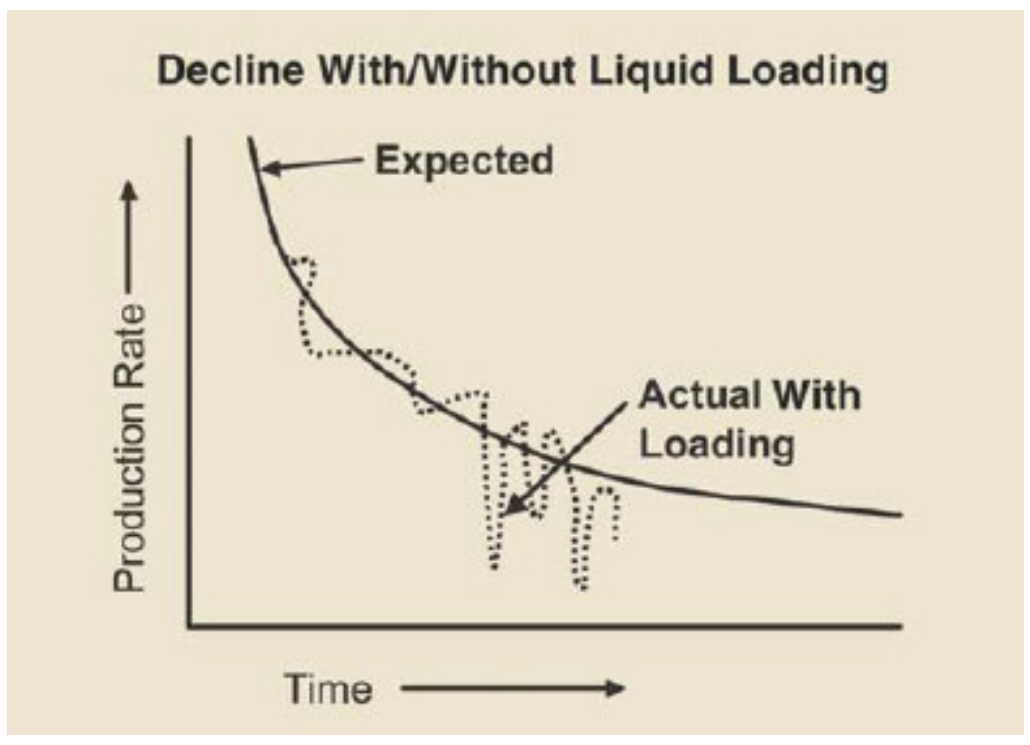

Fig. 2.3 - Decline curve showing onset of liquid loading (Lea, 2004).

O Onset of liquid slugs at the surface of the well

$\circ$ Increasing difference between the tubing and casing flowing pressure (i.e. $p_{c f}-p_{t f}$ ) with time, measurable without packers present

- Sharp changes in gradient on a flowing pressure survey 


\subsection{Remedial Lifting Options to Reduce Liquid Loading Problem}

Many types of technique of remedial lifting have been developed so far. Most of the techniques focus on increasing gas velocity and artificially waterlifting to reduce liquidloading problems. The following table (Veeken, 2003) shows the remedial measures depending on the purpose of use. These methods may be used singly or in combination of two or more.

Table 2.1 - Remedial Measures to Reduce Liquid Loading (Veeken, 2003)

\begin{tabular}{|c|c|}
\hline Classification & Techniques \\
\hline Increase gas velocity & 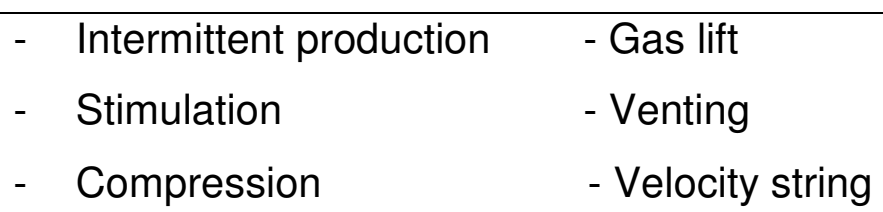 \\
\hline Reduce critical velocity & $\begin{array}{ll} & \text { Compression } \\
- & \text { Velocity string } \\
\text { - } & \text { Mechanical liner solutions (stinger) } \\
\text { - } & \text { Batch soap sticks / surfactant } \\
\text { - } & \text { Continuous surfactant injection } \\
& \text { (capillary strings) } \\
- & \text { Bubble breakers (restriction) }\end{array}$ \\
\hline Artificially lift water & $\begin{array}{ll}- & \text { Plunger } \\
\text { - } & \text { Chamber (plunger plus lift gas) } \\
\text { - } & \text { Downhole pump (rod, PCP, ESP) } \\
\text { - } & \text { Swabbing }\end{array}$ \\
\hline Remove water & $\begin{array}{l}\text { - Downhole separation \& Injection } \\
\text { (intermittent production) } \\
\text { - } \quad \text { Heated tubing }\end{array}$ \\
\hline
\end{tabular}


Different classification is shown below, which is presented by C-FER Technologies in 2007. According to the map of deliquification options, we can first divide into 4 categories: Reduce water influx, Lift gas and water together, Wellbore separation, and Shut-in well. Wellbore separation further categorizes in two ways: lift water to surface separately and downhole water disposal.

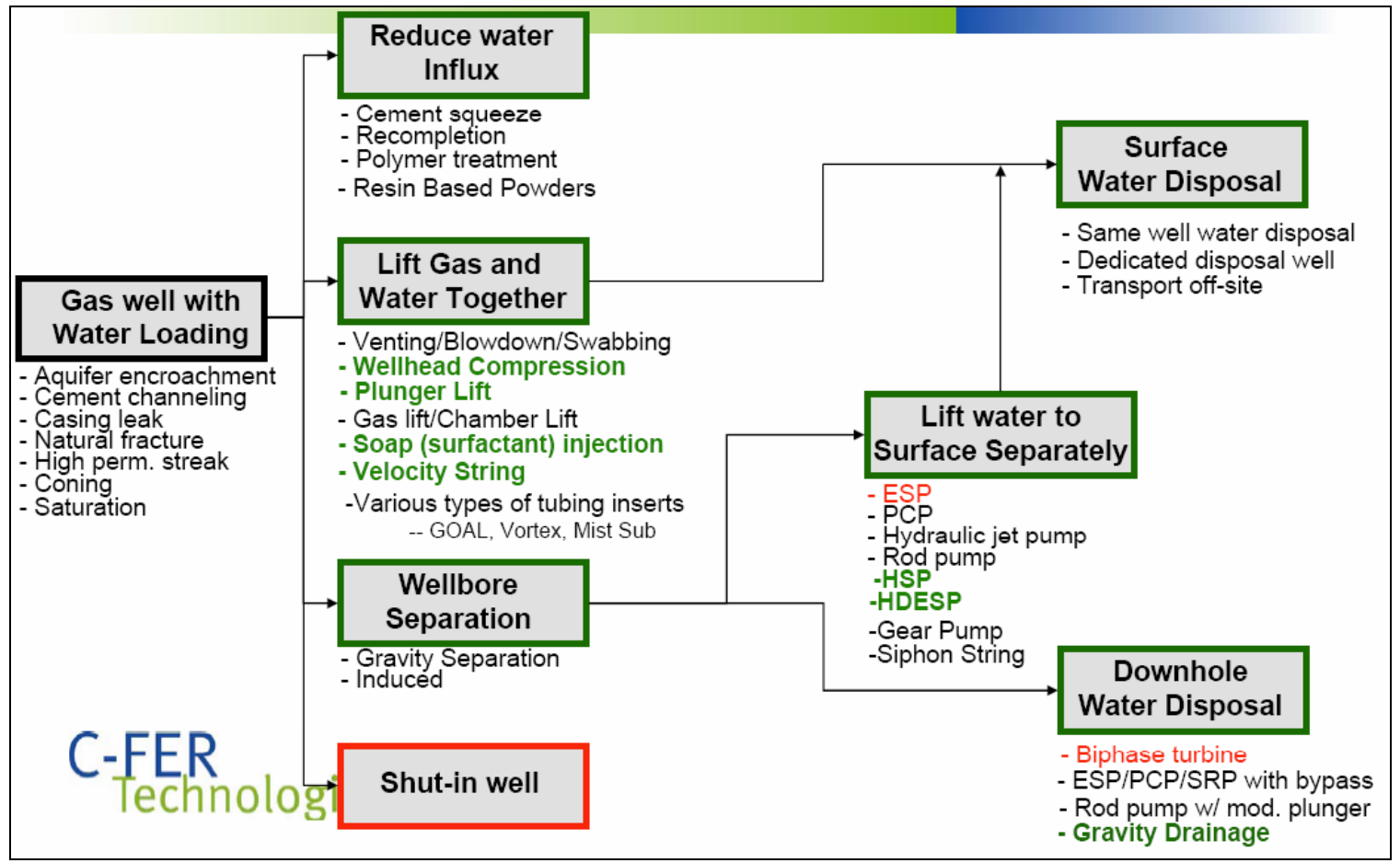

Fig. 2.4 - Map of deliquification options (Piers, 2007)

The remedial options have their own technical characteristics, meaning that the use of them can vary depending on the situation of the well. Thus, at the designing stage, their characteristics should be well-reviewed for the best resolution. In next chapter, 
frequently used techniques are reviewed to discern their applications, advantages, and disadvantages.

\subsubsection{Plunger Lift System}

\section{$\underline{\text { Operation }}$}

A plunger lift system uses gas pressure buildup in a well to lift a column of accumulated liquid out of the well. Basically, the plunger lift system utilizes a plunger traveling up and down inside the tubing to lift the liquid.
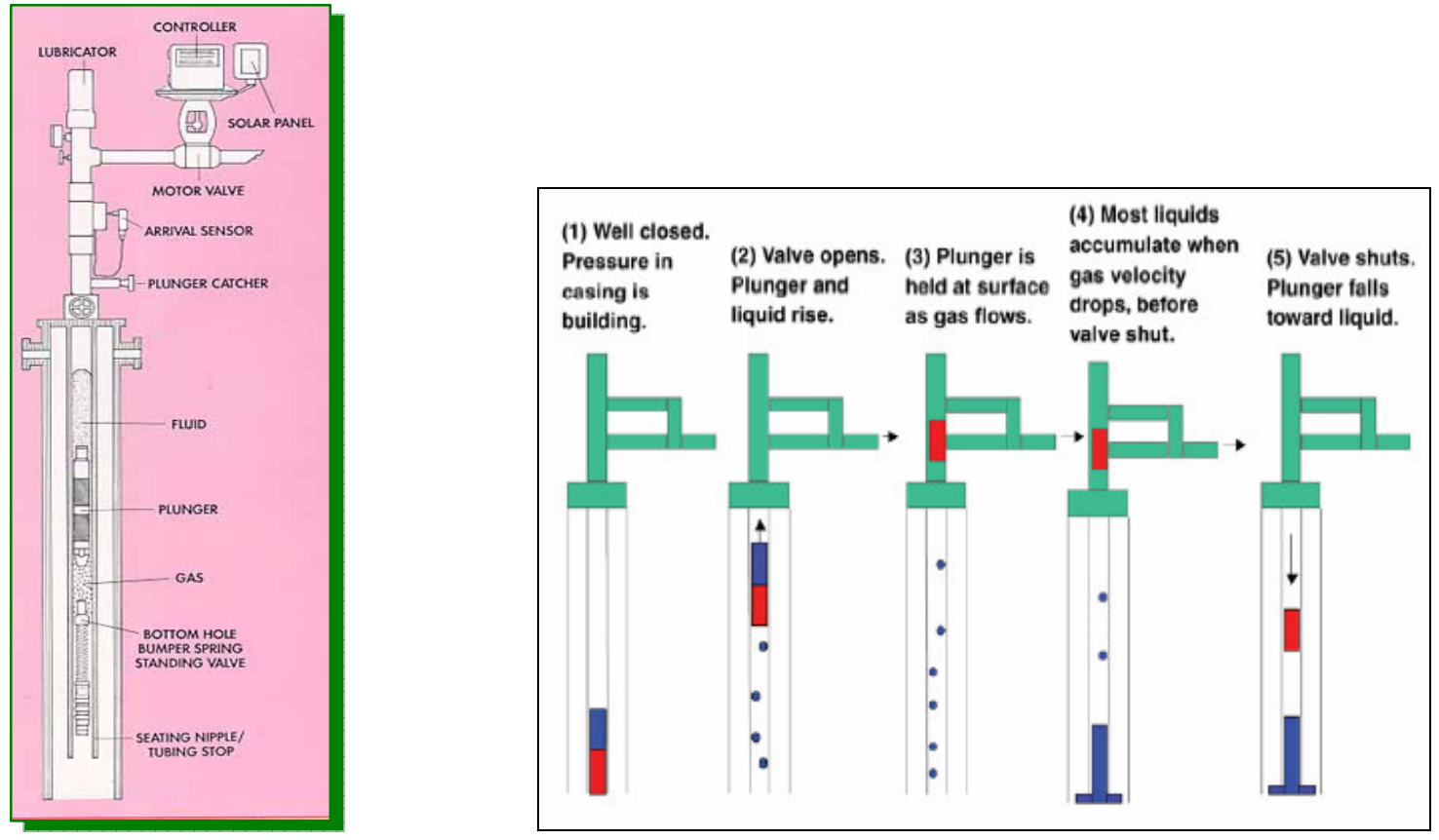

Fig. 2.5 - Plunger lift installation

Fig. 2.6 - Plunger lift cycle (Lea et al., 2004)

Thus, the operation of the plunger system relies on the natural buildup of pressure in a gas well while the well is shut-in. The shut-in pressure of the well must be higher than 
the sales-line pressure to move plunger. The figures above show typical plunger lift installation (Fig. 2.5) and plunger lift operation cycle (Fig. 2.6).

\section{$\underline{\text { Applications }}$}

A plunger system is good at removing liquid in gas wells if the well has sufficient GLR and the pressure is enough to lift the plunger and liquid slugs. Common applications for plunger lift are as followings:

○ Gas wells with liquid loading problems;

○ Intermittent gas lift wells with fallback problems;

- Wells with scale and paraffin problems;

- Oil production with associated gas.

In order to apply the plunger system, there are additional specific requirements or limitations. Wells must produce at least $400 \mathrm{scf} / \mathrm{bbl}$ per $1,000 \mathrm{ft}$ of depth, meaning that high gas-liquid ratio is required to apply plunger system (EPA, 2003). The other limitation is that the wells should have shut-in pressure that is 1.5 times of sales line pressure (EPA, 2003).

\section{$\underline{\text { Advantages / Disadvantages }}$}

The greatest advantage of the plunger system is the cost. It is very cost effective method: lower installation and lower operation cost. This system requires no outside energy source to operate because it uses the well's natural energy. The plunger enables 
the well to clean off paraffin deposits so it is useful for the wells experiencing paraffin and scale problems.

\subsubsection{Gas Lift}

\section{Operation}

A gas lift system is operated by injecting external gas into the production flow stream at some depth in the wellbore. Thereby, it reduces the hydrostatic pressure and enables reservoir production to be improved. The components of a gas lift system are gas source to inject, surface injection system (compressor, control valves, etc), downhole gas lift equipment (valves, mandrels), and surface processing systems (separators, control valves). For the design of gas lift, we need to analyze how much gas needs to be injected and where it should be injected.

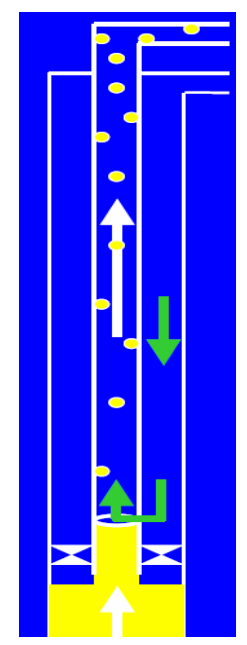

Fig. 2.7 - Gas lift (Veeken, 2003). 


\section{$\underline{\text { Applications }}$}

A gas lift system applies to continuous or intermittent flow. When the well is not as economic with continuous gas lift, as occurs when bottomhole pressure declines, the well is converted to intermittent gas lift. The converting time is when production rate is about 200bbl/day (Lea, 2003). The applications for gas lift are summarized below:

○ Tubing and casing flows;

- Wells available to get supply pressurized gas for injection;

- Well with insufficient bottomhole pressure;

○ Relatively high GLR wells.

\section{$\underline{\text { Advantages / Disadvantages }}$}

Compared to the other methods, it is simple to operate and also its installation cost is not expensive. Sand and other solids can be handled efficiently. A gas lift is also effective in crooked holes. Corrosion and gas can be handled well by a gas lift system. However, for a deep well with low bottomhole pressure, it is not good for application.

\subsubsection{Electric Submersible Pump (ESP)}

\section{$\underline{\text { Operation }}$}

Many different types of pump are available today. Size, capacities, and operating voltages of a pump vary. The ESP system is composed of an electric motor, a protector, a gas separator, a pump, and cable. Typically, ESP systems are adjusted for the high liquid production wells. In a gas well that needs to lift the liquid accumulated in 
wellbore, ESP installation can be designed. The design should focus on the treatment of gas come in pump assembly. Three different methods to remove liquid in gas wells are discussed:

○ Gas separation before coming to pump assembly by using completions or special separation techniques;

○ Pumping gas at special stage and then move to conventional operation;

- Placing pump below perforation let gas flow up the annulus while water falls by gravity to the pump intake (liquid re-injected into a formation below packer).

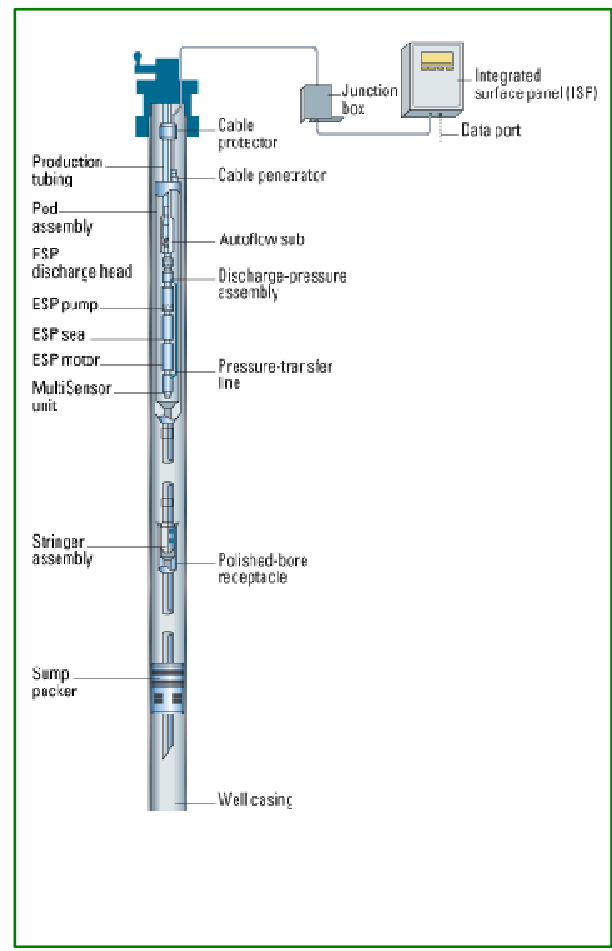

Fig. 2.8 - ESP system (Schlumberger, 2007). 


\section{$\underline{\text { Applications }}$}

The ESP system is typically reserved for application of the well producing primarily liquid. In gas wells, ESP can be applied when it is necessary to handle large liquid volume. The other considerations for application are summarized below:

○ Water rates exceed at least 100bpd (Lea, 2003);

○ High volume lift requirement (100 30,000bpd) (Weatherford, 2007);

○ Deep wells / deviated wells;

○ Waterflood or high water-cut wells

\section{$\underline{\text { Advantages / Disadvantages }}$}

ESP system can be applied at low bottomhole pressure and in crooked wells. Usually it is advantageous over other methods in high volume of production wells. In terms of disadvantages, special considerations are required in cases of high volume of gas production because the high-volume gas inside pump can cause gas interference or severe damage if the system is not installed properly. Installation cost is high and the system needs a little more power consumption. Also, the availability of electric power, particularly high voltage of electric $(1,000 \mathrm{~V}$ or higher), is critical to consideration.

\subsubsection{Progressive Cavity Pump (PCP)}

\section{$\underline{\text { Operation }}$}

PCP is a type of a sucker rod pumping unit that uses a rotor and a stator. This system consists of a surface drive, a downhole pump, and a stator that is attached to the 
bottom of a production tubing string. The fluid contained in a cavity can be flowed up by rod rotation using an electric motor at the surface.

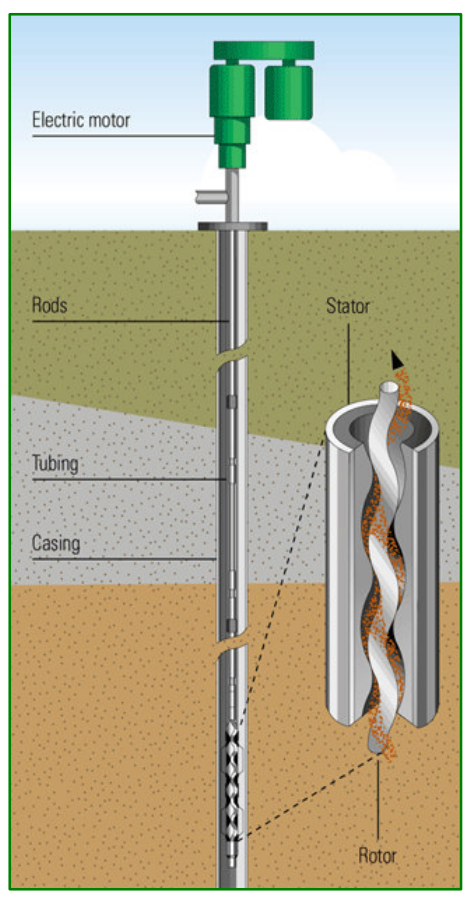

Fig. 2.9 - PCP system (Schlumberger, 2007).

\section{$\underline{\text { Applications }}$}

PCP can be applied to the wells producing sand-laden heavy oil and bitumen, high water-cut wells, and in the gas wells that require dewatering. Operating depth is somewhat limited, as it is believed that the maximum depth of operation is $6,000 \mathrm{ft}$ (Weatherford, 2007). Well's deviation is not a factor, so PCP is applicable regardless of hole deviation. 


\section{Advantages / Disadvantages}

Solid and gas handling is good or excellent while corrosion handling is just fair. This system can be installed and operated economically due to low capital investment and power consumption. Compared to other pumping methods, it is able to operate more quietly.

\subsubsection{Sucker Rod Pump}

\section{$\underline{\text { Operation }}$}

Rod pump system consists of a surface pumping unit, a rod string, and a pump. The liquid is lifted by the reciprocating pumping action of the surface unit attached to the rod string. The liquid comes into the assembly at the downstroke, and then be lifted at the upstroke of rod.

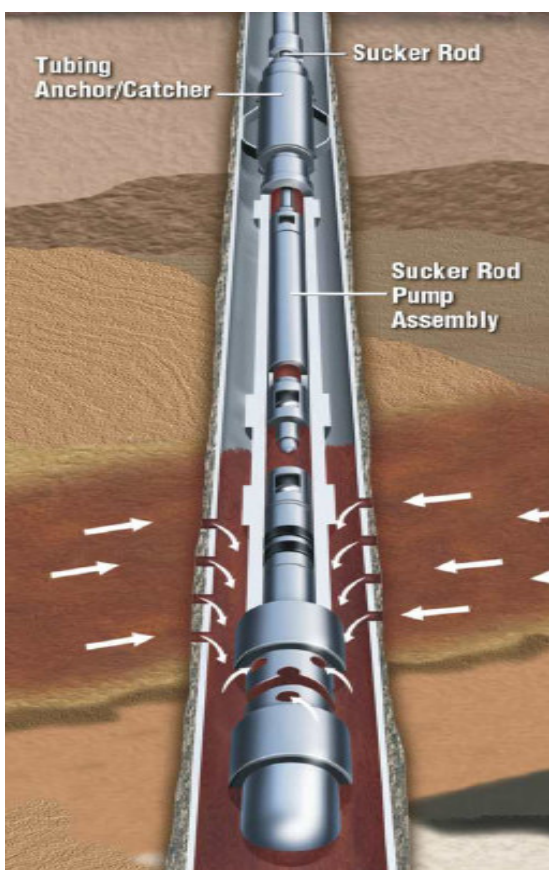

Fig. 2.10 - Sucker rod pump system (Weatherford, 2007). 


\section{$\underline{\text { Applications }}$}

Sucker rod pump has very broad applications:

- Applicable to sandy fluid, gaseous, high viscosity;

○ All types of wells: horizontal, slant, directional and vertical well.

\section{$\underline{\text { Advantages / Disadvantages }}$}

Sucker rod pumping systems have been used widely, and are very familiar to most operating workers. This system is highly reliable and easy to analyze. High temperature or viscous liquid can be produced. It is economical to repair and service. However, this system has some disadvantages. In crooked holes, for example, this system is not appropriate. The depth and volume necessary to operate by this system are limited because of rod weight and strength considerations. The overall size and weight of this system may prohibit its offshore application.

\subsubsection{Jet Lift / Piston Lift}

\section{Operation}

The hydraulic lift systems, jet lift and piston lift, consist of a surface power fluid system, a prime mover, a surface pump, and a downhole jet or reciprocating/piston pump. 


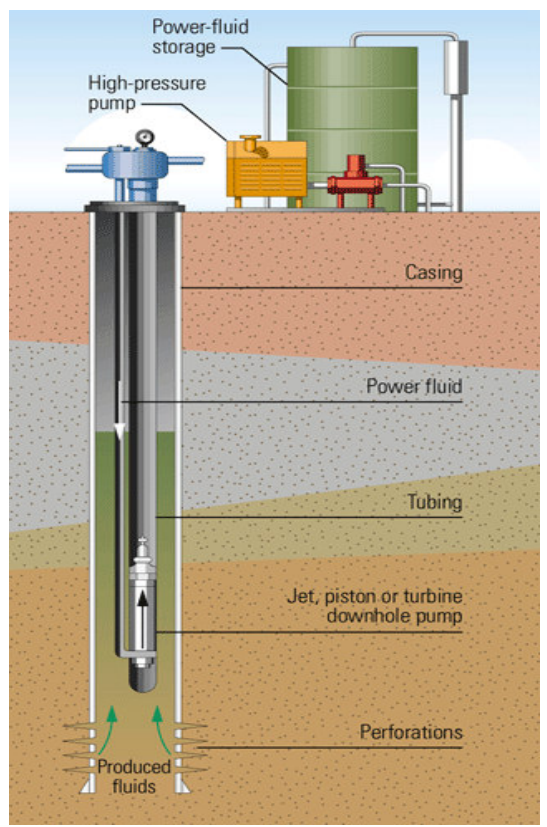

Fig. 2.11 - Hydraulic pumping (Schlumberger, 2007).

The power fluid (oil or water) is supplied from power-fluid storage in surface to downhole pump through the wellhead valve. In a piston pump installation, power fluid actuates the pressurized piston engine on top of the pump, and then the fluid returns to the surface with accumulated liquid.

In case of jet pump, the nozzle works for converting high-pressure, low velocity energy of the power fluid to high-velocity, low-pressure energy. In the throat the power fluid is mixed with the low-pressure pump intake fluid. Then, the velocity energy of this mixed stream is then moved to the diffuser which converts it to static pressure to provide the pressure necessary to bring the fluid to the surface. 


\section{$\underline{\text { Applications }}$}

These hydraulic pumps are commonly adaptable to all types of wells (deviated, horizontal, and vertical wells). These systems are efficient in multiple well installations. The other applications are summarized below:

- Applicable to API $10^{\circ}$ gravity or higher fluid (Weatherford, 2007);

- Applicable to sandy or fluid containing solids;

- Applicable to high volume and high depth wells.

\section{Advantages / Disadvantages}

Both jet and piston pump are easy to maintain. Downhole pumps can be circulated out for maintenance or can be retrieved by wireline. Paraffin can be handled well by heating or chemically treating the power fluid. Produced fluids with high sand content or other abrasives may cause problems. Initial costs for pumping installation are high, and operation and maintenance works are not easier than the sucker rod pump system. 


\subsection{Current Development Status on Prediction of Liquid Loading and Selection of Remedial Options}

As examined in the previous section, many remedial options have been developed so far. They have been proven in the field to reduce the loss of gas production when liquid loading begins to occur. As they have different characteristics in terms of technical, environmental and economical views, a choice is always required whenever they meet liquid loading problem. However, the choice may be not easy because each option's feasibility and cost vary dependent on the field's location, size, its export route, etc. No generic tool or model has been developed to help the designer select the most appropriate option. Internal efforts within individual operators have been made to build such a tool but no success due to wide geographical variations of issues and costs.

Table 2.2 - Ranking Remedial Measures (Veeken, 2003)

\begin{tabular}{|l|c|c|c|c|}
\hline \multicolumn{1}{|c|}{ Measure } & $\begin{array}{c}\text { Ultimate } \\
\text { Recovery }\end{array}$ & Capacity & Cost & Risks \\
\hline 1. Water shut-off & + & + & + & 0 \\
\hline 2. Stimulation & + & + & + & - \\
\hline 3. Compression & + & + & - & + \\
\hline 4. Foam lift & + & 0 & + & - \\
\hline 5. Gas lift & + & 0 & - & 0 \\
\hline 6. Velocity string & + & - & 0 & - \\
\hline 7. Downhole pump & + & 0 & -- & - \\
\hline
\end{tabular}


Some examples that have been made to develop such a tool or model from the industry are introduced in the following. Veeken ranked (June 2003) remedial measures, as shown in Table 2.2. This table shows that the remedial options can be ranked on the basis of four aspects (ultimate recovery, capacity, cost, risks). The characteristics of the options are well-described in this format, which can be used in preliminary selection of options. However, in the detailed design stage, it is not enough because a more complicated and detailed comparison is required for the best optimization.

Another attempt was done by Schlumberger. From their recent report, it is known that they tried to solve and manage liquid loading problems by integrated method: analyzing the available well data, defining actual status and well performance, diagnosing the well, selecting the most suitable production system, managing the data, and optimizing the operation. To define the well model and adjust the actual production data with simulated well behavior, the composite system (NODAL) analysis has been implemented by software (Pipesim). Once the well model has been verified, system analysis evaluates the future well behavior and selects the appropriate production systems by comparing the results from different input parameters and conditions. Also, system analysis completes the diagnosis work to find the causes that decreased gas production. 


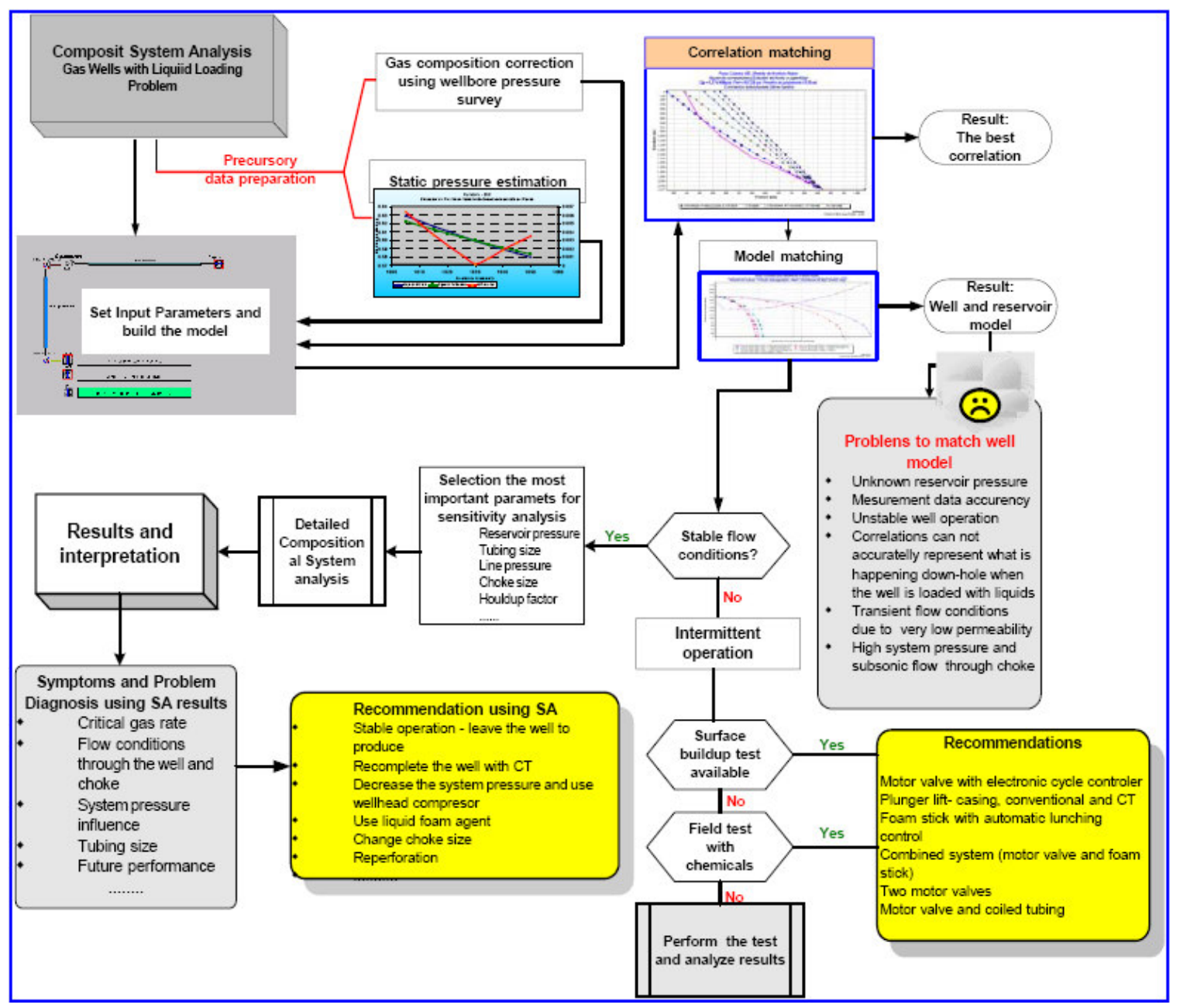

Fig. 2.12 - Well performance model for gas wells with liquid loading problem

(Schlumberger, 2006).

In Fig. 2.12, the flow chart of the procedure for defining well performance is shown. However, this system analysis is useful only if enough data acquired so that the most appropriate method for solving liquid loading problem can be selected. If the data is too limited to do system analysis, then multi-criteria ranking analysis has been suggested to identify the best choice of remedial option. 
For details on the multi-criteria ranking method, Schlumberger (2006) defined factors determining liquid loading and influencing the selection of the method, and then grouped into the following general classes (GFC):

○ Well completion

- Well production and pressure history

- Well performance class

○ Laboratory tests

○ Field tests

O Other problems and tests

○ Costs

From the general classes (macro level) defined above, the subclasses (micro level) of parameters with defined importance are extracted. Here, the general classes are criteria to evaluate remedial options and have sub-criteria (called subclass). Integrated Evaluation Factor (IEF) is defined by the following calculation;

$$
I E F=\sqrt[n]{\prod_{i=1}^{n} G F C_{(i)}}
$$

Then, the method having the highest IEF value is recommended for application. The particularly important thing is how to give an evaluation number. Here, a five-level (0 to 4) evaluation system has been used in model development. The evaluation of this method arises from the description table already made, and the level of importance of certain parameter alters as a function of final effectiveness of applied method. A sample 
evaluation matrix table can be found at Fig. 2.13 to help demonstrate how the multicriteria model is applied.

\begin{tabular}{|c|c|c|c|c|c|c|c|c|}
\hline & \multicolumn{8}{|c|}{ Pozo:Culebra-24 } \\
\hline CRITERIA & \multicolumn{8}{|c|}{ EVALUACIÓN DE VARIOS METODOS } \\
\hline Well Completion & Foam & Plunger & $\begin{array}{l}\text { Compreseor } \\
\text { at weellhead }\end{array}$ & $\begin{array}{l}\text { Int. Flow wth } \\
\text { matar walve }\end{array}$ & \begin{tabular}{|l|l|} 
Small \\
Thyg 10 \\
\end{tabular} & \begin{tabular}{|l|l|} 
\\
\end{tabular} & \begin{tabular}{|l|l} 
ESP & $C$ \\
\end{tabular} & Gas ifrt \\
\hline With Packer & 4 & 2 & 4 & 2 & 4 & $\begin{array}{ll}+1 \\
: 1\end{array}$ & 1 & 4 \\
\hline Paker set $>-30 \mathrm{~m} y<60$ open interval & 4 & 1 & & 3 & 3 & 1 & 2 & 3 \\
\hline Vertical & 4 & 4 & 4 & 4 & 4 & 4 & 4 & 4 \\
\hline Well Is shallow < $1500 \mathrm{~m}$ & 4 & 4 & 4 & 4 & 4 & 4 & 4 & 4 \\
\hline Medium $C s y \mid D<4.5^{\prime \prime}=<7^{\prime \prime}$ & & 4 & & 4 & 2 & 3 & 4 & 3 \\
\hline Evaluation & 4.00 & 2.64 & 3.94 & 3.29 & 4.43 & 2.63 & 3.36 & 4.90 \\
\hline \multirow[t]{2}{*}{ Well Production History } & \multirow[t]{2}{*}{ Espou. } & \multirow{2}{*}{ Embolo } & \multirow{2}{*}{$\begin{array}{l}\text { Compresor en } 1 \\
\text { boea del pozo }\end{array}$} & \multirow{2}{*}{ Filulo Int.con } & \multirow{2}{*}{$5 v$} & \multirow[t]{2}{*}{ BM } & \multirow[t]{2}{*}{ ESP } & \multirow[t]{2}{*}{ BN } \\
\hline & & & & & & & & \\
\hline Low gas production ic 0.3 MMApCd) & 4 & 2 & $\mathbf{0}$ & 2 & 4 & 4 & 4 & 4 \\
\hline Erratic & 3 & 4 & 2 & 4 & 4 & 2 & 2 & 2 \\
\hline Ho liquid type informetion & 1 & 3 & 1 & 4 & 1 & 1 & 1 & 1 \\
\hline Evaluation & 1.44 & 2.29 & 1.26 & 2.52 & 1.59 & 1.26 & 1.26 & 1.26 \\
\hline Wellhead pressure history & Espu. & Embolo & $\begin{array}{c}\text { Compresor en la } \\
\text { boca del pozo }\end{array}$ & $\begin{array}{l}\text { Fluio Int.con } \\
\text { Volvule Motore }\end{array}$ & sv & BM & ESP & BN \\
\hline Decrease atruptly & 3 & 4 & 4 & 4 & 4 & 2 & 2 & 2 \\
\hline Law & 4 & 3 & 3 & 4 & 1 & 3 & 3 & 2 \\
\hline Considerably less than expected & 3 & 1 & 2 & 2 & 1 & 4 & 4 & 4 \\
\hline Evaluation & 2.27 & 2.27 & 2.29 & 2.52 & 1.59 & 1.82 & 1.82 & 1.59 \\
\hline \begin{tabular}{|l|} 
Well \\
Performance
\end{tabular} & Esput. & Embolo & $\begin{array}{c}\text { Compresor en la } \\
\text { boca del pozzo }\end{array}$ & \begin{tabular}{|l|} 
Flivio Int.con \\
Válvule Motora
\end{tabular} & Sv & $8 \mathrm{M}$ & ESP & BN \\
\hline Gas production has been decreasing during measurement & 2 & 4 & 4 & 4 & 3 & 1 & 1 & 2 \\
\hline Low gas production & 3 & 2 & 0 & 3 & 4 & 4 & 4 & 3 \\
\hline No se tine irformation de produccion de liquldo & 1 & 3 & 1 & 4 & 4 & 1 & 1 & 1 \\
\hline Ihg pressurre increment curve have two or more slants with stathilization & & 3 & & 3 & & & & \\
\hline Itgg pressure declinex rapidly without stabilitzation and $x L^{P}$ & & 3 & & 3 & & & & \\
\hline Shut in Tbg pressure (SIIP) is greater than 2.22 .6 line pressure & & 4 & & 1 & & & & \\
\hline Critical velocity is ureater than yas lest rate & 4 & 4 & 2 & 4 & 4 & 3 & 3 & 3 \\
\hline Line pressure is low & 4 & 4 & 4 & 4 & 4 & 4 & 4 & 4 \\
\hline Iemperature at hottomis media ( $>80 \mathrm{C}<<150 \mathrm{C}$ ) & 4 & 4 & & & & 4 & 3 & 4 \\
\hline Evaluation & 2.69 & 3.36 & 0.00 & 3.12 & 3.78 & 2.39 & 2.28 & 2.56 \\
\hline $\begin{array}{c}\text { OTHER } \\
\text { PROBLEMS } \\
\end{array}$ & Espu. & Embolo & $\begin{array}{c}\text { Compresor en la } \\
\text { baca del pazo }\end{array}$ & $\begin{array}{l}\text { Flijo Int.con } \\
\text { Váluuta Motora }\end{array}$ & sv & вM & ESP & в \\
\hline Content of Carbon Dioxid low & 4 & 4 & 3 & 3 & 3 & 4 & 4 & 4 \\
\hline No sand protuction & 4 & 4 & 4 & 4 & 4 & 4 & 4 & 4 \\
\hline Mechanical tallure of casing & 3 & 0 & 4 & 4 & 3 & 1 & 1 & 1 \\
\hline No H2S & 4 & 4 & 4 & 4 & 4 & 4 & 4 & 4 \\
\hline Evaluation & 3.72 & 0.00 & 3.72 & 3.72 & 3.46 & 2.83 & 2.83 & 2.83 \\
\hline COSTS & Espu. & Embolo & $\begin{array}{c}\text { Compresor en las } \\
\text { boca del pozzo }\end{array}$ & $\begin{array}{l}\text { Flijo Int.con } \\
\text { Valwula Motore }\end{array}$ & sv & BM & ESP & BN \\
\hline Operating cost & 3 & 4 & 1 & 4 & 0 & 0 & 0 & 0 \\
\hline Equipment (installation) cost & 4 & 4 & 1 & 4 & 0 & 0 & 0 & 0 \\
\hline Evaluation & 3.46 & 4.00 & 1.00 & 4.00 & 0.00 & 0.00 & 0.00 & 0.00 \\
\hline Final Score & 2.76 & 0.00 & 0.00 & 3.13 & 0.00 & 0.00 & 0.00 & 0.00 \\
\hline
\end{tabular}

Fig. 2.13 - Multi-criteria model (Schlumberger, 2006). 


\subsection{Limitations of Previous Attempts to Select Remedial Options}

The previous section reviewed the relative literature and current development status of the selection of remedial options for solving liquid loading problem. Fieldproven solutions already exist for reducing the loss of gas production in gas wells. However, a user-friendly and generic decision matrix doesn't exist even after previous efforts and achievements on the development of such tool. As we examined, the matrix by Veeken (2003) is too simple to be used as a generic tool for the selection of lifting options even though the characteristics of the options are well-described in the matrix. The matrix, in other words, doesn't cover specific consideration factors affecting the selection of lifting options. Schlumberger's model relies on running software and system analysis, and therefore requires much data from the field and much time to do analysis with software; thus, it is not useful in speeding up the decision making process between when the first symptoms of liquid loading and the severe impact on a gas well's production.

Under such circumstances, this thesis proposes a newly developed decision matrix to quickly screen the possible remedial options available to the operator. The matrix can not only provide a critical evaluation of potential solutions to the problem of liquid loading in gas wells in relation to the existing technical and economic constraints, but can also help operators make investment decisions and as a quick screening tool for the selection of remedial techniques. 


\section{CHAPTER III}

\section{METHODOLOGY AND APPROACH TO DECISION MATRIX}

\subsection{Possible Approaches: Data Mining Techniques}

What is data mining? Data mining refers to extracting or mining knowledge from large amounts of data, and is called "knowledge discovery in database (KDD)." It is the exploration and analysis of large quantities of data in order to discover meaningful patterns and rules (Berry et al., 2004) or a process to help discover patterns and relationships in data that we use to make valid predictions. Why are we considering using data mining techniques for this project? As we discussed before, we may gather as much field experience data as we can, data related to production under operation of remedial lifting options; then, we need to develop a tool that enables us to select appropriate remedial option by analyzing the data and extracting valuable information from them. Once we are ready to analyze the data, the first thing to do is to describe the data, summarize its statistical attributes, visualize it using charts and graphs and catch its patterns, and find out meaningful relationship among variables. The next thing is to build a predictive model based on patterns and relationship. Then, we need to test the model by using new data different with original dataset. Once the test is done, final verification of the model is required.

There are different prediction types and various model types of data mining techniques. Prediction types are divided into two categories, classification and regression. Classification predicts the category or class the data may fall into, while regression 
means to predict what number value a variable will have. There numerous model types: neural network, decision trees, multivariate adaptive regression splines (MARS), rule induction, K-nearest neighbor and memory-based reasoning (MBR), logistic regression, matrix decomposition, and so on. To apply data mining techniques, we have to decide which type of prediction and type of model is going to be adjusted to our project. The most important model types of data mining are described below.

\subsubsection{Neural Network}

A neural network is used in classification problems (output variable is categorical) or for regressions (output variable is continuous). The basic structure of a neural network is shown in Fig. 3.1. It consists of an input layer, hidden layers, and output layers that are interconnected. The output of a neural network relies on the cooperation of the individual neurons within the network to operate.

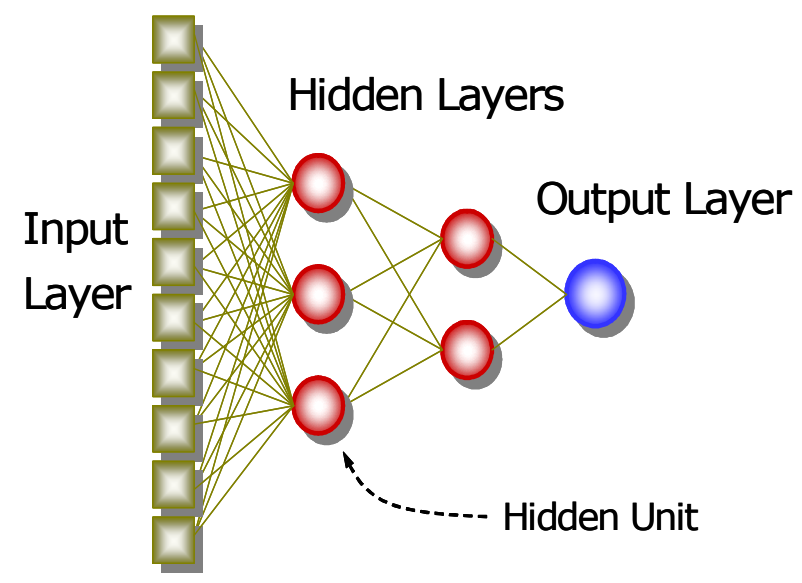

Fig. 3.1 - Neural network structure. 
In detail, each node takes in a set of inputs and multiplies them by a given weight $\mathrm{W}_{\mathrm{xy}}$. Then, the node adds them together, applies a function to them, and passes the output to the node in the next layer. Fig. 3.2 shows how it works.

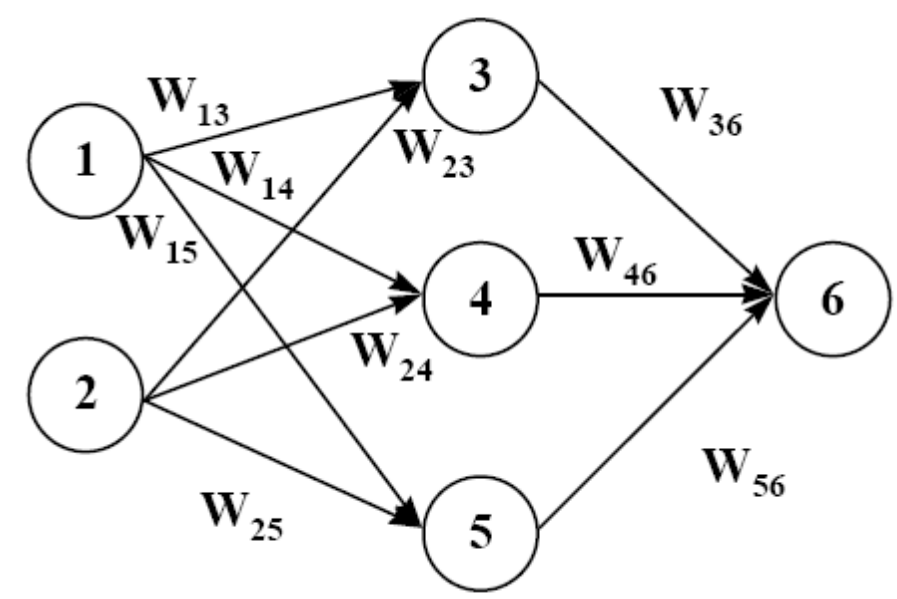

Fig. 3.2 - Neural network activation (Twocrows, 2007)

The connection weights are unknown values which are decided by a training method. For training, backpropagation method is commonly used. Simply speaking, backpropagation is an algorithm designed to reduce a target value error by finding the difference between the calculated output and the desired output. In this industry, we can find applications of neural network method easily. For example, neural network method was used to identify the well performance and define the well model by training neural network with real production data. Specifically, a prediction of bottomhole pressure and reservoir temperature was conducted by neural network, and it was also used to identify flow patterns in gas wells. 


\subsubsection{Decision Tree}

Decision tree is a structure that can be used to divide a large set of data into successively smaller sets by applying a series of decision rules. This division then leads to a class or value. For example, Fig. 3.3 shows a simple decision tree to illustrate all the basic components of a decision tree: decision node, branches and leaves.

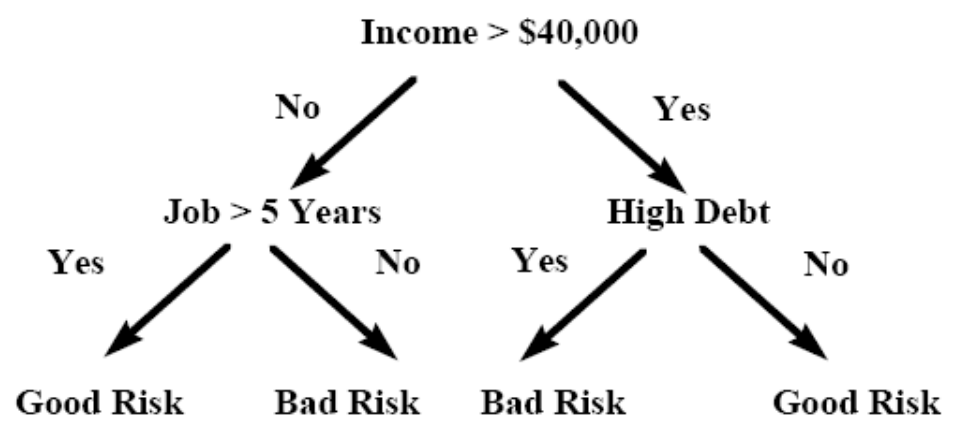

Fig. 3.3 - Example of decision tree (Twocrows, 2007)

As shown in Fig. 3.3 above, the root node in the top of tree, Income $>\$ 40,000$, specifies a rule to be conducted. In this case, we have two possible answers (either "Yes" or "No"); therefore two branches are taken. In continuity, the tree is going to be grown depending on expected rules and the resulting branches will be split into discrete groups. In some cases, two or more branches can be made, but each branch is going to lead to different decision node finally. In this particular characteristic of decision tree, the model is commonly used in data mining to examine the data and categorize it by tree shape, 
then make its rules that will be used in predictions. The advantages of decision tree are summarized below:

○ Very fast at classifying unknown records

- Easy to interpret for small-sized trees

- Accuracy is comparable to other classification techniques for many simple data sets

○ Excellent to handle non-numeric data

\subsubsection{Matrix Decomposition}

Many data mining techniques implicitly assume that there is a single explanation for each data value that appears in a dataset, and they try to build a model that explains such data. However, in many real datasets, this view is too simple: the data values are the result of the interaction of several overlapping processes, each of which has made some contribution to each value (Skillicorn et al., 2003). Because of this, the matrix decompositions are useful methods because they are able to separate these contributions of different processes to datasets.

The following techniques are known as kinds of matrix decompositions:

- Singular value decomposition (SVD) and principal component analysis (PCA)

- Semidiscrete decomposition (SDD)

- Independent component analysis (ICA)

$\circ \quad$ Non-negative matrix factorization (NNMF) 
All of these techniques show how to decompose a dataset matrix, A, into a form like Equation below.

Eq. 3-1

$$
\mathbf{A}=\mathbf{U} \Sigma \mathbf{V}
$$

From now on, the singular value decomposition (SVD) method and interpretation method are explained. Where $\mathrm{U}$ and $\mathrm{V}$ are orthogonal, $\Sigma$ is a diagonal matrix. The matrix $A$ is matrix with $m$ rows and $n$ columns. $U$ is $m$ by $n, V$ is $n$ by $n$, and $\Sigma$ is $n$ by $n$. A matrix $\mathrm{U}$ is orthogonal if the matrix multiplied by its transpose is an identity matrix, that is, $\mathrm{U}^{\mathrm{T}} \mathrm{U}=\mathrm{I}$.

The matrix $\Sigma$ contains the singular values on the diagonal. The matrix $U$ contains the left singular vectors, and the matrix $\mathrm{V}$ contains the right singular vectors. The transpose of matrix A multiplied by $\mathrm{A}$ is a square matrix, and any square matrix admits a spectral decomposition into eigenvectors and eigenvalues. The singular values of $\mathrm{A}$ are the square roots of the eigenvalues of $\mathrm{A}^{\mathrm{T}} \mathrm{A}$.

For interpretation of SVD, the geometric method is usually used. The geometric interpretation regards the rows of $U$ as coordinates of the objects in the space spanned by new axes, the rows of $\mathrm{V}$ (columns of $\mathrm{V}^{\prime}$ ) as defining new axes, and $\sum$ as a scaling factor indicating the relative importance of each new axis. Since SVD is a decomposition that rotates the original space in such a way that the variance is maximized along the first axis, the remaining variance is maximized along the second axis, and so on. Fig. 3.4 and 3.5 illustrate how SVD works. 


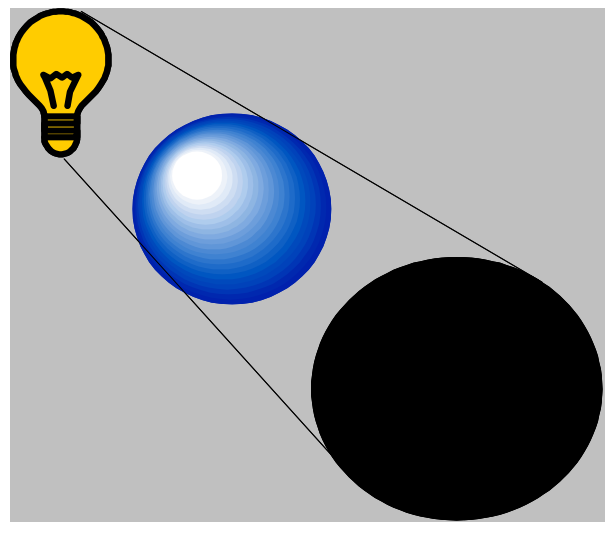

Fig. 3.4 - Projection (1).

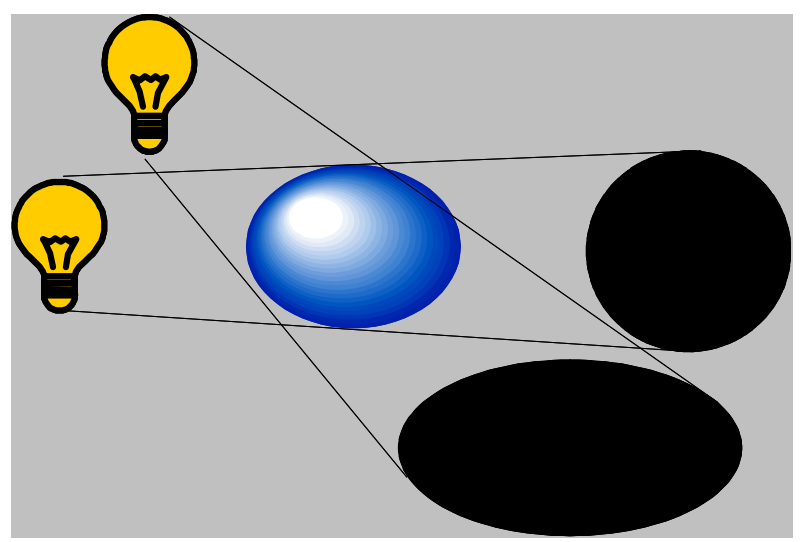

Fig. 3.5 - Projection (2).

Fig. 3.4 shows that the shadow of a sphere will always be a circle (two dimensions) regardless of the location of light. In contrast, Fig. 3.5 shows that the ellipsoid shadow is either an ellipse or a circle. From these figures, following statements can be made:

- Any two-dimensional projection of a sphere will convey all of the information necessary to reproduce the sphere. There is no best projection.

- An ellipsoid has a best projection: the projection that produces the ellipse with the longest major axis. Rotating this ellipse about the major axis perfectly reproduces the ellipsoid.

○ In a least squares sense, the SVD produces a "best" projection.

- If the SVD reduces $M$ attributes to $m$ SVD linear combinations of the $M$ attributes, then these $\mathrm{m}$ linear combinations provide the best m-dimensional representation of the original M-dimensional space.

As explained above, the SVD preserves the information in the original matrix, A, even though the dimensionality is reduced. 


\subsubsection{K-nearest Neighbor and Memory-Based Reasoning (MBR)}

K-nearest neighbor technique is based on the concept of similarity, which is a classification technique. This technique decides in which class to place a new case by examining some number, the " $\mathrm{K}$ " in k-nearest neighbor, of the most similar cases or neighbors as seen in Fig. 3.6 (from Two Crows Corporation). From the figure we can decide that $\mathrm{N}$, new case, is assigned to the class $\mathrm{X}$ because the seven $\mathrm{X}$ 's within the ellipse outnumber the two Y's. The number of cases for each class is important in order to assign new case to the same class most of its neighbors belong to. The measures of distance and similarity are important to K-NN technique. To apply K-NN method we need to measure the distance between attributes in the data. Then, we will select the set of already classified cases to use as a basis for classifying new cases and need to decide both the range of neighborhood and method to count the neighbors.

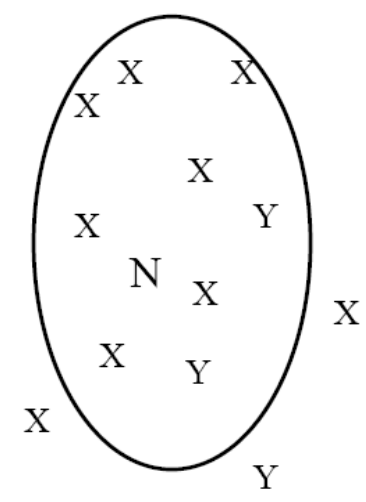

Fig. 3.6 - Example of K-NN (Twocrows, 2007) 
$\mathrm{K}-\mathrm{NN}$ method is good at classifying numeric data, but it requires some special consideration to handle categorical variables. K-NN needs much computational work, so it takes more time compared to other methods such as neural network. To reduce working time or to speed up the process, memory-based reasoning (MBR) can be used which keeps all the data in the memory. The advantages of this method are that K-NN is very easy to understand in case few predictor variables exist and it is a useful method for building a model composed of non-standard data type.

\subsection{Approach Chosen for This Work}

Besides the four data mining techniques we discussed above, there are different types of data mining techniques still used in the industry. For this work, among various datamining techniques, we chose to use a decision tree to build the decision matrix for solving liquid loading problems, because a decision tree is useful for the classification and is easy to understand and interpret. The decision tree helped to streamline the initial information for this project in a more rapid and efficient manner than other techniques. The output from a decision tree is easier to interpret, and a decision tree can be readily coded in a simple program, as was done for this project. On the basis of a decision tree, the same selection procedure can be implemented by means of other data mining techniques. 


\subsection{Consideration Factors in Selection of Techniques}

The selection of an appropriate lift option is critical to the project profitability. The proper artificial lift can improve productivity by removing liquid effectively and eventually raising project economics. On the contrary, a bad choice cannot be expected to improve production and adversely affects the economics of project. There are many factors that need to be considered when selecting an artificial lift option. These factors include site information like location, well characteristics, producing characteristics, fluid properties, power availability, surface facilities, reservoir characteristics, operation concerns, completion type, service availability, and economic points. Due to the great amount of factors affecting the selection of remedial techniques, it was clear since the beginning of this work that not all factors could be included in the decision matrix. In particular, it was immediately noted that different operators may give a different level of importance to different decision parameters. However, this work aims to be as exhaustive as possible, on the basis of the information that was available.

\subsubsection{Site Information (Location)}

The production facilities are installed differently depending on the well's location, especially the surrounding environment. The offshore well needs to install all surface facilities on the platform with limited aerial extent. Thus, special considerations are required to utilize concentrated area. For this reason, some artificial lifts requiring spacious area may not be used. Also, the logistics on equipment and power is difficult to 
establish compared to onshore. We can summarize that the main issues of offshore wells are like follows:

- Footprint of equipments;

$\circ$ Costs;

- Access for operation and maintenance of equipments;

- More specific problem is for plunger lift system when downhole safety valve (DHSV) is installed in offshore wells.

Regardless of well location, either onshore or offshore, we are given the regulations or approval conditions to observe, which are imposed by authorized organizations (e.g. government). Such conditions generally include safety rule, environmental protection rules, and pollution treatment plans, etc. For instance, some artificial options making high noise should be excluded if it is not able to meet the condition.

\subsubsection{Well Characteristics}

Well characteristics like depth, deviation, and size of tubular are the most significant criteria in the selection process for an appropriate artificial lift. As discussed in the previous chapter on artificial option attributes, each option has its own limitations on depth, deviation, and tubular size. It is said that the depth may have little effect in determining the method of artificial lift. However, if we need to design an artificial lift for a very deep well below 15,000ft, depth may indeed be a factor. In this case, there are limited options available to be applied due to their maximum depth of operation. 
Depending on the amount of deviation of hole, the efficiency of each lifting option is different, with efficiency usually reduced. For a highly deviated well or horizontal well, some options are not recommended to be used.

\subsubsection{Producing Characteristics}

According to how much liquid is being produced or how much gas is being produced, the production scheme should be differently made. The production rate in total volume basis is one of the criteria that screen artificial lift options, and the GLR is one of the most important factors in the selection process. For instance, in extremely high rates of production like above $15,000 \mathrm{bpd}$, ESP and gas lift systems can only be considered. On the other hand, with a low rate of production, we can consider all possible artificial lift techniques. GLR places importance on which high gas-liquid ratio wells will be a problem for any method of lift unless proper venting is considered. Specifically, the pumping systems are inefficient if GLR exceeds 500scf/bbl (Lea, 2003).

\subsubsection{Fluid Properties}

The consideration points in fluid properties are viscosity, density, and composition. In general, viscosities less than $10 \mathrm{cp}$ (above $30^{\circ} \mathrm{API}$ ) are not a factor in determining the lift method (Brown, 1980). For instance, sucker rods do not fall down easily for highly viscous fluid, and such a phenomenon results in inefficient production. The fluid composition is important to see if the fluid results in a corrosion problem. 


\subsubsection{Power Availability}

The power sources for artificial lift prime movers are usually electricity or pressurized gas. Most of these wells are located in isolated places far from residency areas. In some situations, it is not useful for a well to be supplied stable electricity from power generation stations. To use pumping systems like ESP and hydraulic pumps, stable electricity should be obtained, but for gas lift system, high pressurized gas is required to supply securely.

\subsubsection{Surface Facilities}

Surface facilities like flow lines, choke valve, and separators are to be considered when choosing a proper lifting method. In general, they need to be designed in such a way that one can accommodate new equipment (method for liquid unloading).

\subsubsection{Reservoir Characteristics}

Reservoir characteristics is a factor that should be considered in order to make a production plan that figures out how much it will be produced monthly and how further time it will be produced. Based on production remaining time and production rate, the selection of lifting method can be made.

\subsubsection{Operation Concerns}

Here, the operation concerns include, but are not limited to:

○ Scale 
- Corrosion

$\circ$ Erosion

○ Emulsion

○ Formation/Deposition of hydrates

In addition, bottom-hole temperature and surface climate are also consideration points in operation. Sand causes erosion problems for all types of artificial lift methods. Downhole corrosion may be caused by electrolysis between different metal types, H2S or $\mathrm{CO} 2$ content in the produced fluid, highly saline or saturated brine water, or oxygenation of metals (Brown, 1980). For paraffin, once it is accumulated in the upper tubing string or flow-line, it will cause pressure drop. Scale deposition will decrease flow efficiency by reducing ID of tubing.

Bottomhole temperature is one of factors that should be considered before final selection, because very high temperatures in bottomhole will damage equipment like pump motor and cable. Lifting equipment capable of operating over certain high temperatures should be selected.

\subsubsection{Service Availability}

Some types of lifting methods require work-over or pulling units in time of service or replacement, while other types of methods can be serviced by using wire-line. Sometimes the methods may be sensitive in terms of operation cost. Basically, checking points about service availability are to investigate which service personnel, replacement parts, and service rigs or equipment are available. 


\subsubsection{Economic Point}

Generally, we consider economic point of view in the last stage of selection process after technical evaluation is done. If several options are verified for application from a technical point of view, we will evaluate their influence on economics of project. The capital expenditure, operation expenditure, expected income, and other economic factors (e.g. equipment life of time, etc.) will be considered and the result of economic evaluation will be used eventually when the final decision is made. 


\section{CHAPTER IV}

\section{DEVELOPMENT OF DECISION MATRIX}

\subsection{Introduction}

The primary purpose of this research is to build decision matrix to screen remedial options for liquid loading by gathering and synthesizing field data. Fig. 4.1 below shows the work flow and possible approaches to data mining. We used decision tree method to apply data mining technique to processed data. Eventually, the matrix is targeted to evaluate technical feasibility, chance of success, and cost profitability for each option. The matrix that we built will assist engineers in determining an appropriate option and can therefore be used as a decision tool.

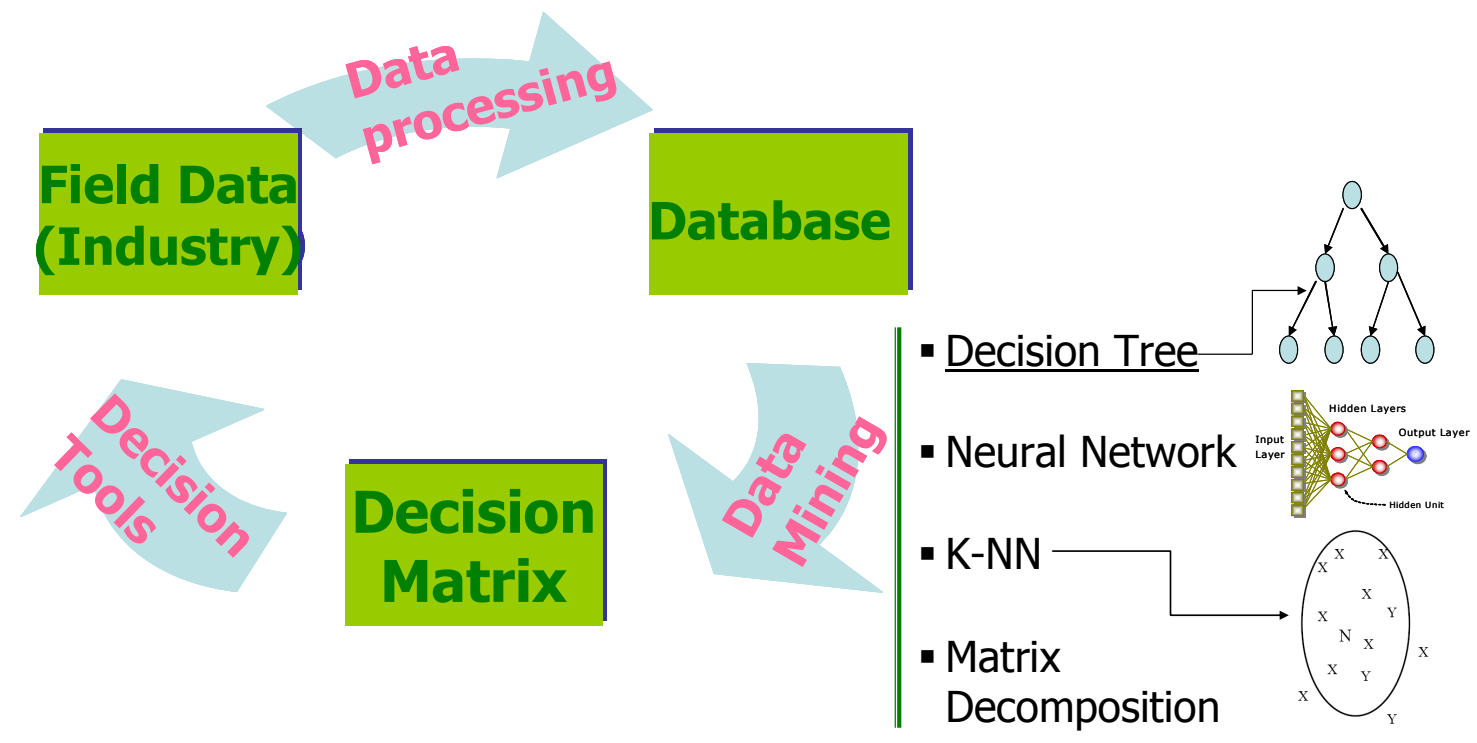

Fig. 4.1 - Work flow and possible approaches to data mining 
For this research, we have done the following;

1) Performed literature review on different remedial techniques of liquid loading problems in gas wells;

2) Gathered available experience data from released papers and analytical/theoretical data from manufacture' documents;

3) Developed decision tree, so called Round 1, to screen remedial techniques preliminary and to aid decision in selecting remedial technique;

4) Developed technical evaluation chart (Round 2) for further screening and evaluating options technically;

5) Developed economic evaluation tool (Round 3) to see cost \& profitability of each option;

6) Built a decision matrix by combining 3 Rounds above. We used Visual Basic Language (VBL) programming to build the matrix.

Following Fig. 4.2 shows the general structure of decision matrix. As stated above, the matrix contains 3 Rounds: Preliminary Screening [Round 1], Technical Evaluation [Round 2], and Economic Evaluation [Round 3]. 


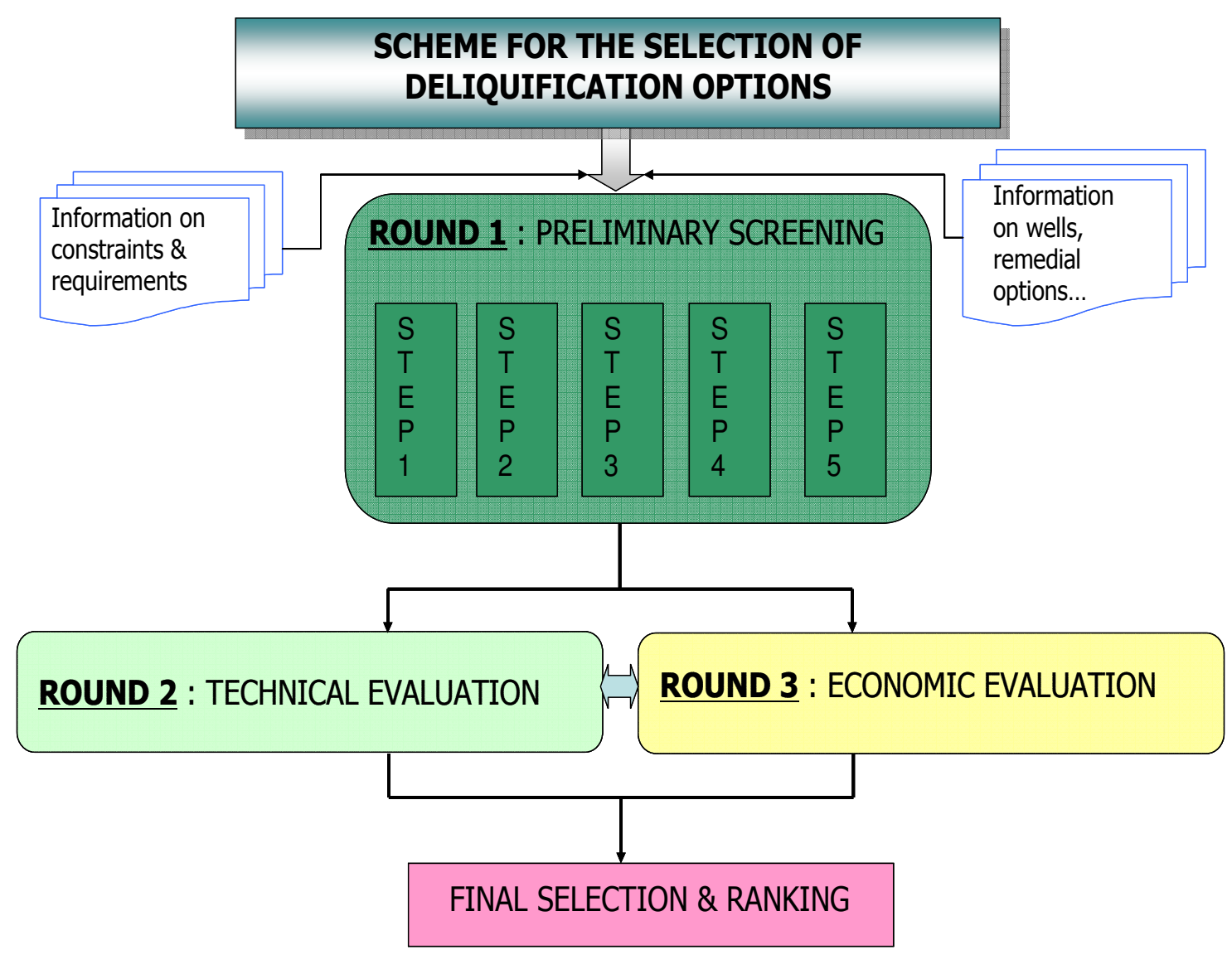

Fig. 4.2 - General structure of decision matrix

\subsection{Decision Tree \& Preliminary Screening [Round 1]}

The decision tree should be composed logically from the starting point to the end point. Also, the tree should eventually suggest a reasonable solution at the end. Using both the gathered information and the comparison chart or deviation table analyzed with each option's characteristics, we discovered which items could be appropriate regarding a corresponding situation that the wells have.

The decision tree has many questions to be answered and action boxes to be conducted as shown in Fig. 4.3. The questions have been divided into several steps for 
differentiation, which are about production situation, fluid characteristics, and production facilities. For example, each question generally asks what condition the well has or what properties the fluid shows. Such questions are designed to find distinctions among remedial options so that, at the end of tree, we can find the best option at the given conditions by removing some options from each step if we follow the tree. In other words, some remedial options should be dropped in case they are not available in the given conditions. Thus, the key point of the decision tree is finding distinctions between options by analyzing the operating availability of each option from experience field data and analytical review data.

The developed decision tree is shown in Fig. 4.3. It is built with 9 steps, from node 0 to node 8 . Each node has at least two branches. We will now move on to a detailed explanation of each node, so how remedial options are screened and what consideration factors have been taken into are discussed below. 


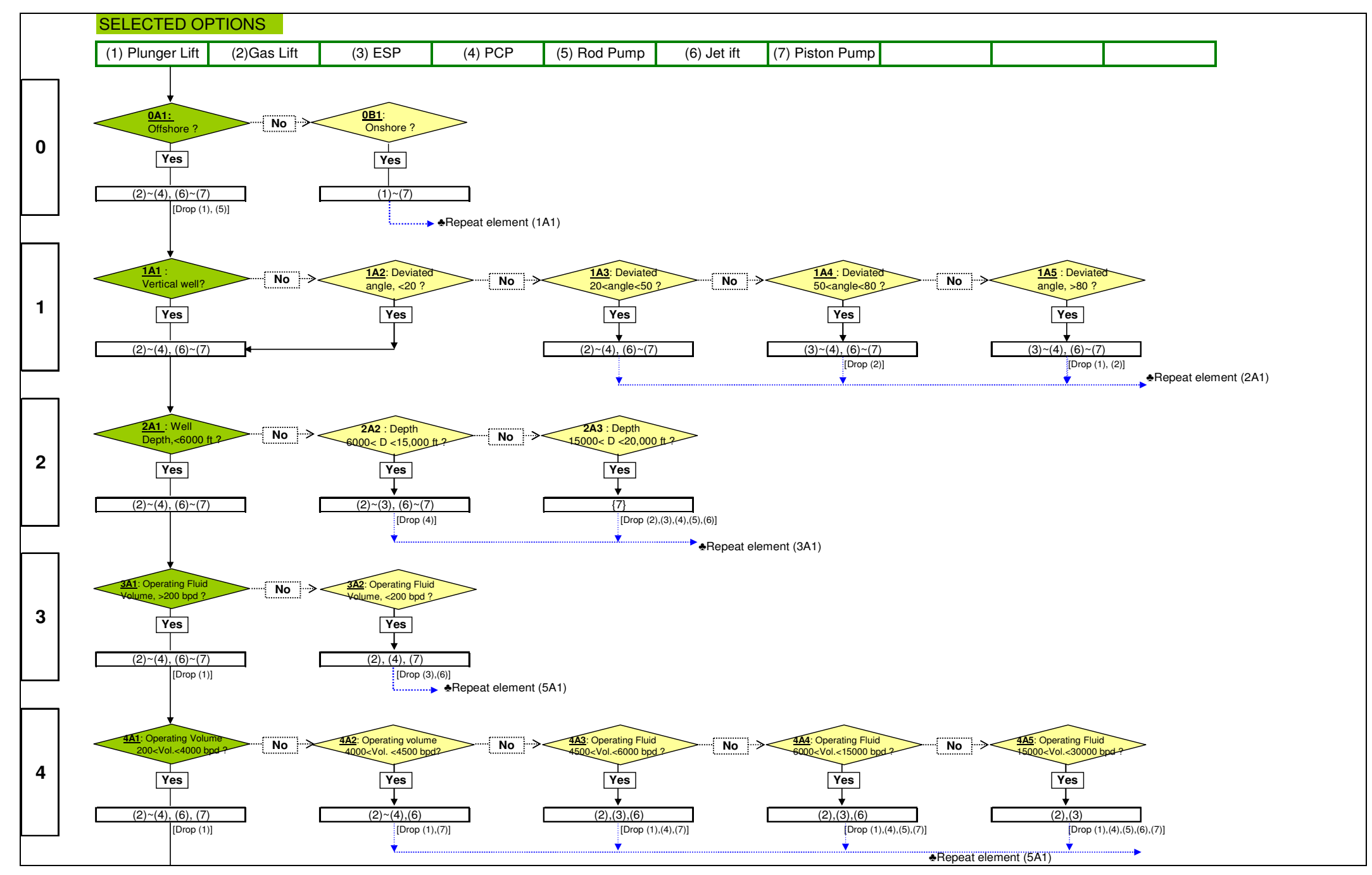

Fig. 4.3 - Developed decision tree to screen remedial options 


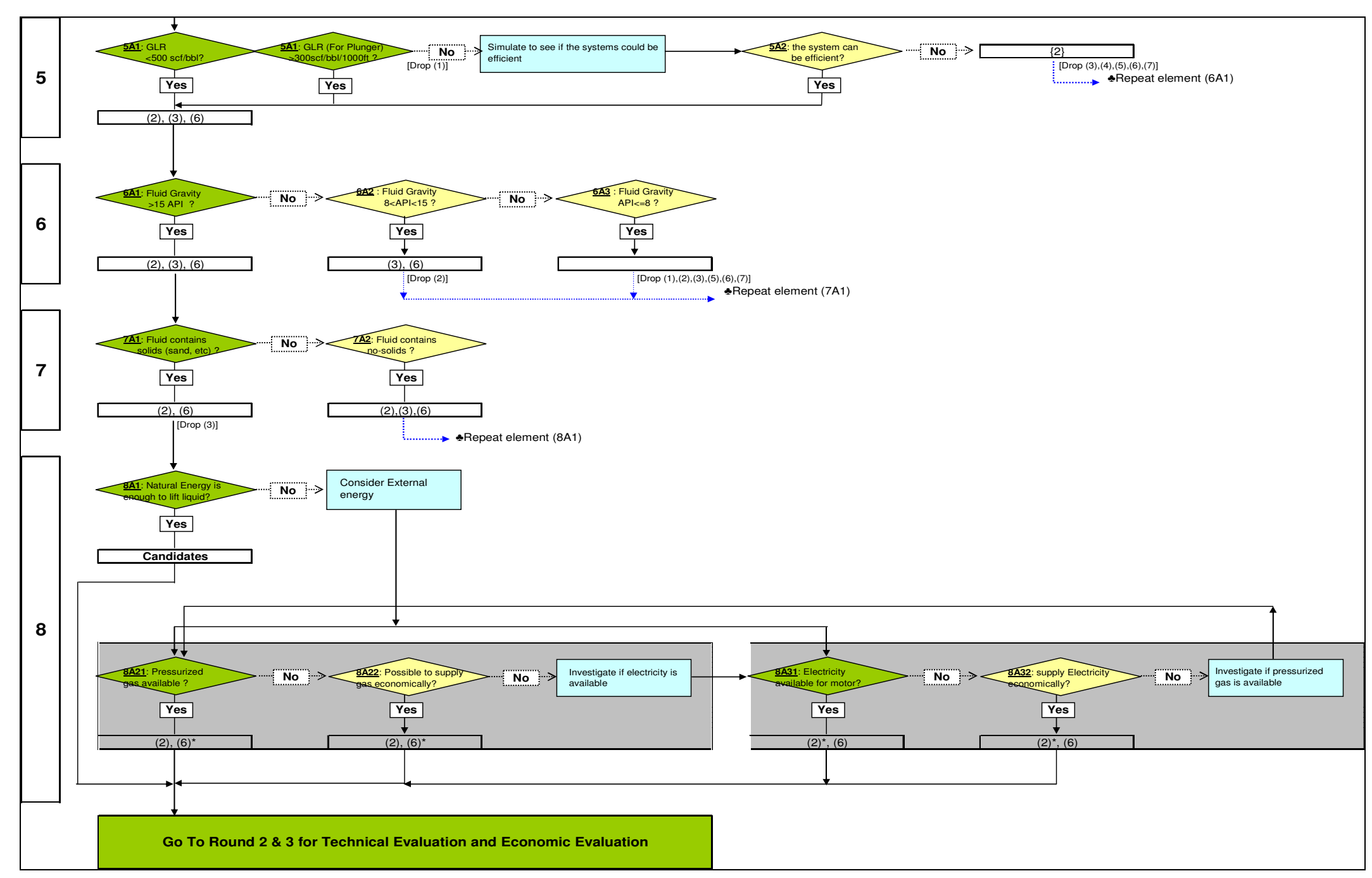

Fig. 4.3 - (Continued) 


\subsubsection{Model Node [0]: Location}

This element asks where the wells are situated, either "offshore" or "onshore". In case of onshore, there is no limitation on applicability of each option. On the other hand, some options are not applicable offshore, specifically the rod pump system is not recommended to be used at the offshore well since its overall weight and size can prohibit use on offshore applications (Richard W. Donnelly, 1985). Also, the plunger system, insert capillary string foam and chemical injection, and progressive cavity pump are difficult to apply on offshore fields in cases where the downhole safety valve (DHSV) has been installed. However, new technology like Torus Insert Safety Valve (by Caledyne Ltd), which is configured to fit capillary tube, fibre optic or electrical penetrators or rotary seals, may enable them to be used. (Journal Offshore, September 2007)

\subsubsection{Model Node [1]: Well Deviation}

This element asks how much the well is deviated. Depending on well deviation, each remedial-technique's availability can be decided and its efficiency is different.. As shown in Fig. 4.4, ESP and PCP are not affected by deviation but the other methods are inefficient or not applicable at horizontal wells. Therefore, we are going to screen gas lift for a well deviated over $70^{\circ}$ and plunger lift method is screened at the horizontal well from Round 1. Then, we need to differentiate them at Round 2 [Technical Evaluation of Artificial lift methods] and evaluate methods that can operate at some high deviation hole. For instance, some methods such as Sucker rod pump, Jet lift, and Piston pump do 
not show high efficiency at high deviated hole, while ESP and PCP do. We will discuss Round 2 in further detail in the next chapter.

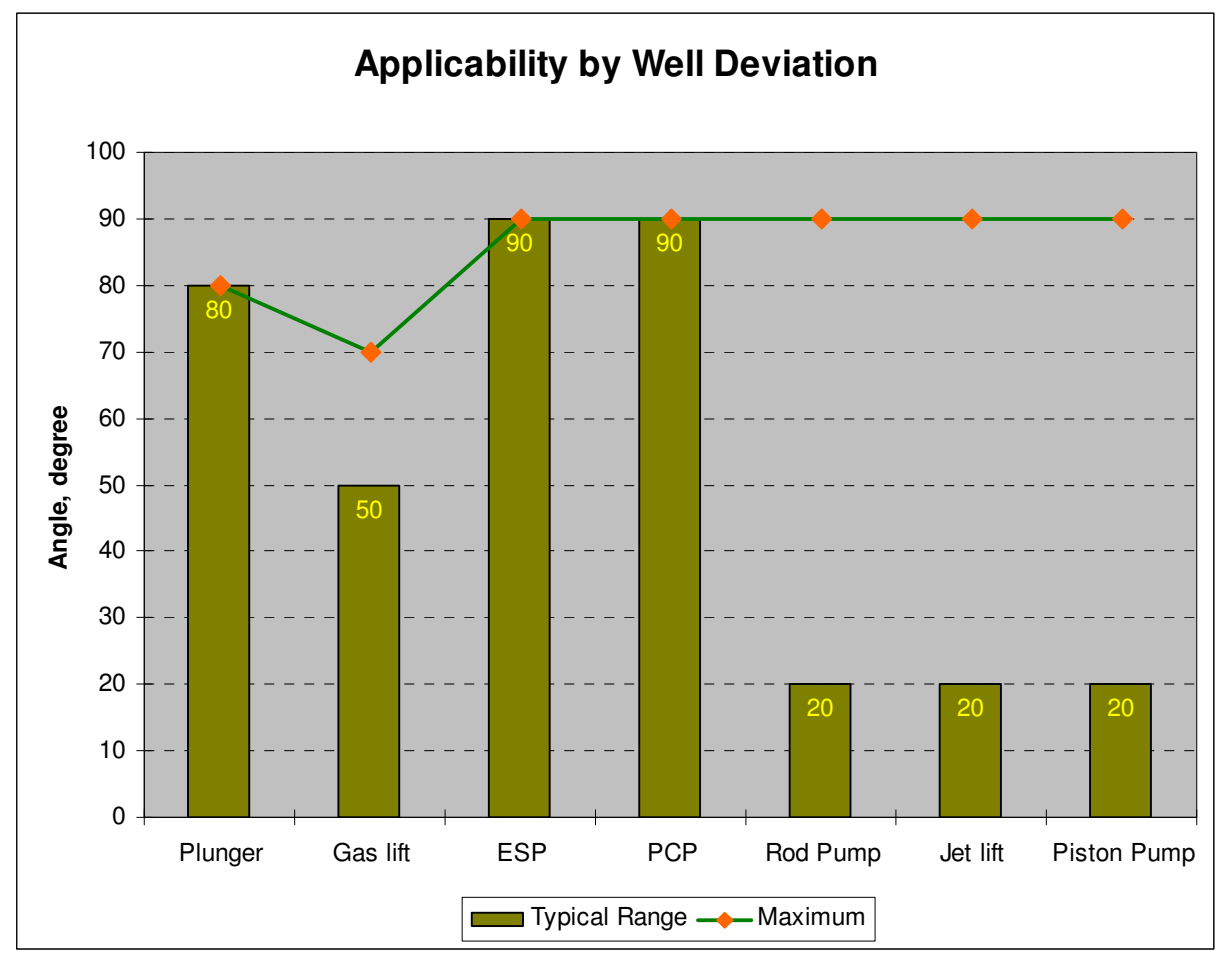

Fig. 4.4 - Applicability of technical remedial options by well deviation (After Weatherford (2007) and Clegg et al (1993))

\subsubsection{Model Node [2]: Well Depth}

Depth will have a strong influence on selection of artificial lift method because each method has capacity limitation of motor or equipment. Using each option's operation depth limit, we are able to choose an appropriate option for the given depth. Fig. 4.5 shows maximum depth to apply and typical operation depth for each option. As you see from the following figure, a well depth of over $6,000 \mathrm{ft}$ is not able to utilize PCP method 
when unloading liquid from the well. For a high-depth well over $15,000 \mathrm{ft}$, three methods (Gas lift, ESP, Jet lift) are limited. Similarly, Rod pump and Piston pump methods are limited to $16,000 \mathrm{ft}$ and $17,000 \mathrm{ft}$ respectively. The experience and performance data shows Plunger system is able to be used at the highest depth if other conditions are met.

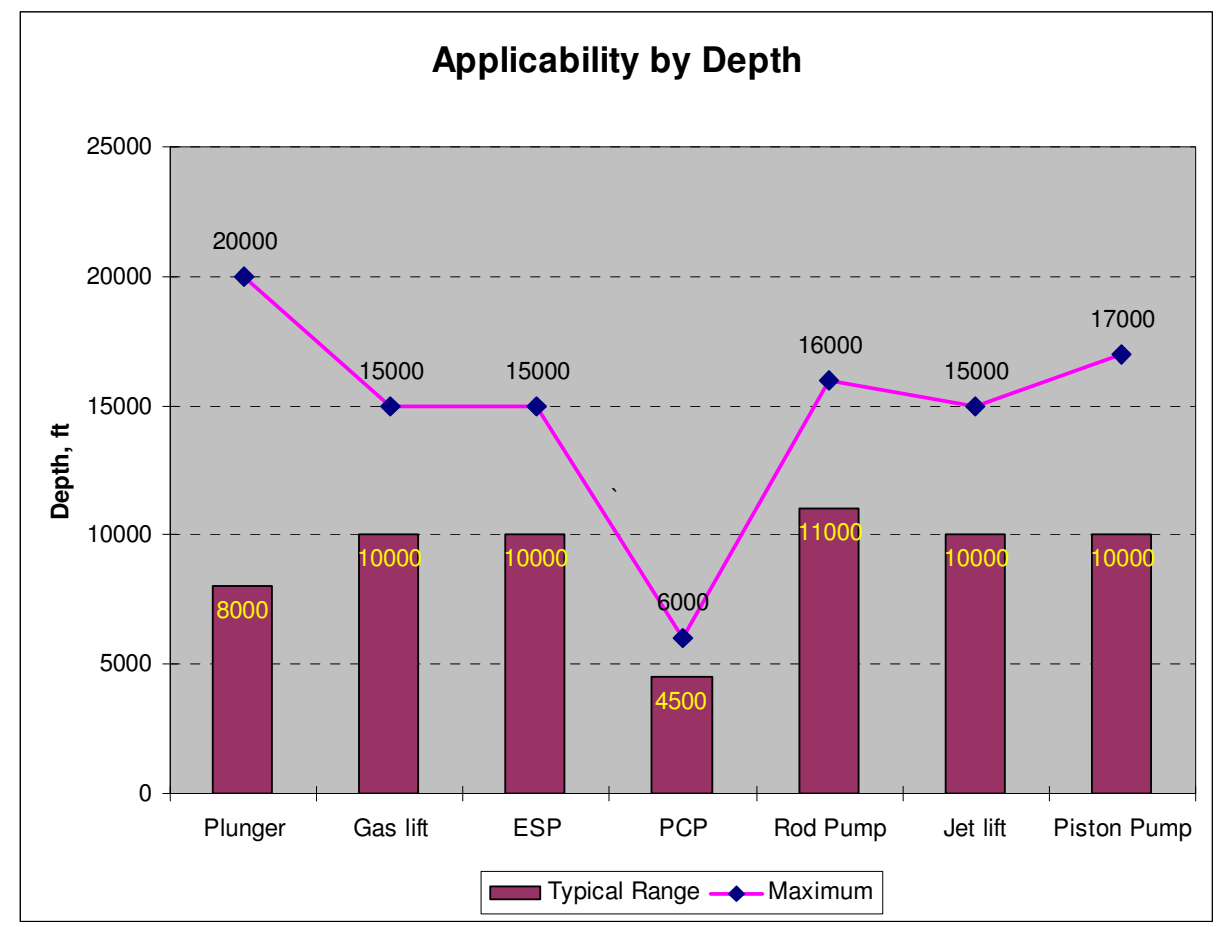

Fig. 4.5 - Applicability of technical remedial options by well depth (After Weatherford (2007) and Clegg et al (1993))

\subsubsection{Model Node [3] \& [4]: Operating Volume Rate}

The total production volume rate is an important factor in the selection of artificial lift method because each lift method has its own operation limits due to its mechanical power capacity. Basically for very low production volume there is no application 
exceptions; however, some of the artificial lift methods are limited to high volume production. The following figure shows typical range of operating volume rate and maximum to operate. Basically, when higher volume rate is operating, less artificial methods are available to use. As shown below, we are able to select appropriate method based on the given operating volume rate. For instance, plunger is removed from possible method if the well is producing fluid over 200bpd. As the volume is larger, Piston Pump is screened at over 4,000bpd, PCP at over 4,500bpd, and then Rod Pump is removed at over $6,000 \mathrm{bpd}$. Jet lift is still available up to $15,000 \mathrm{bpd}$. Remaining two options, Gas lift and ESP, are able to be used up to 30,000bpd.

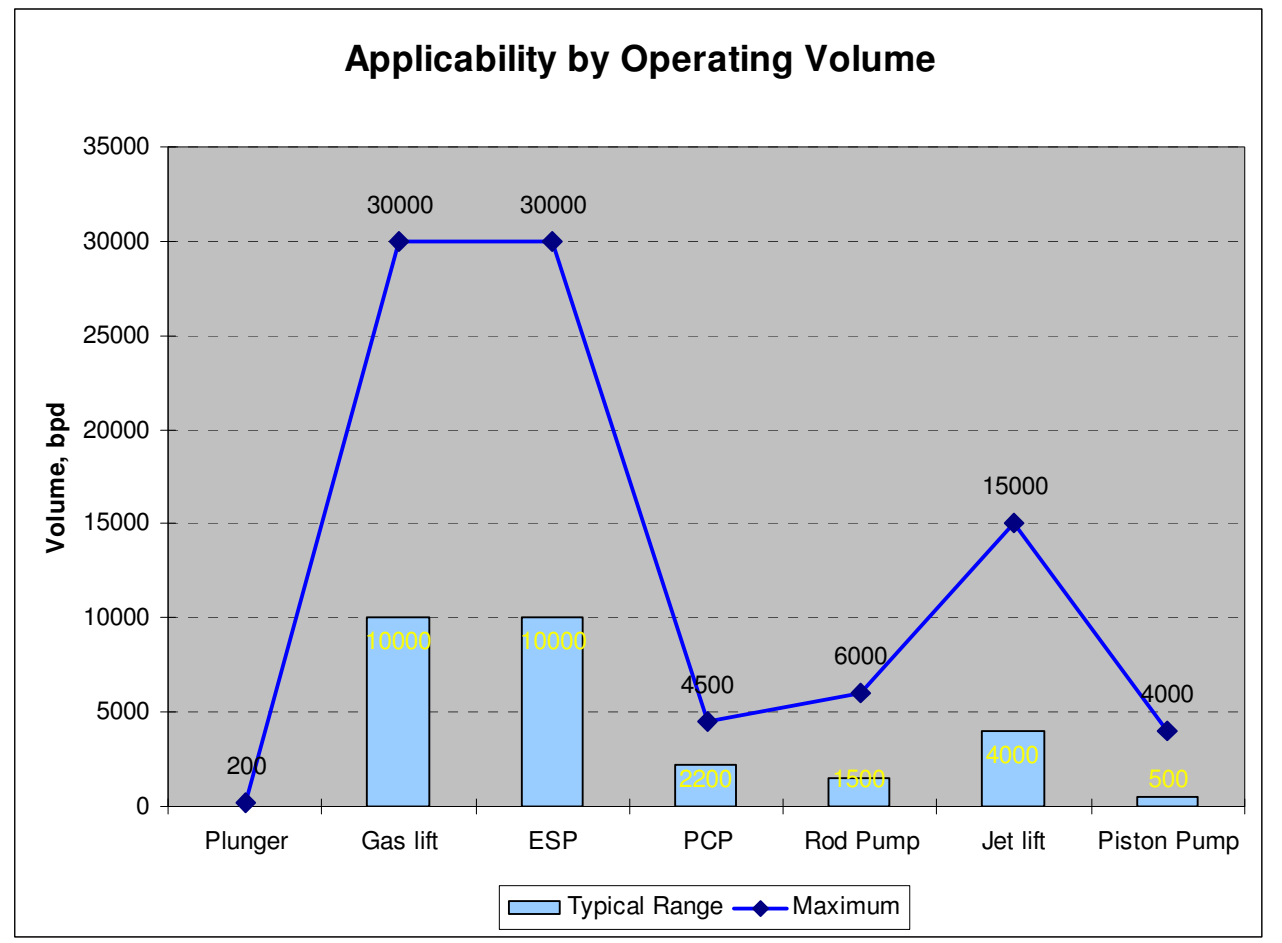

Fig. 4.6 - Applicability of technical remedial options by operating volume (After Weatherford (2007)) 
The figures help us to recognize which method is not applicable to certain depth and volume rates, and provide each option's typical range of operation in terms of depth and volume rate. Now, we are going to look at a figure that shows approximate depth-rate application chart of artificial lift methods. From this chart, we can know what the relationship between depth and rate shows and which method can have bigger range of rate application at certain depth. For example, at 1,000ft, Gas lift that has the largest range is applicable up to $33,000 \mathrm{bpd}$, while Plunger lift has the smallest range of application.

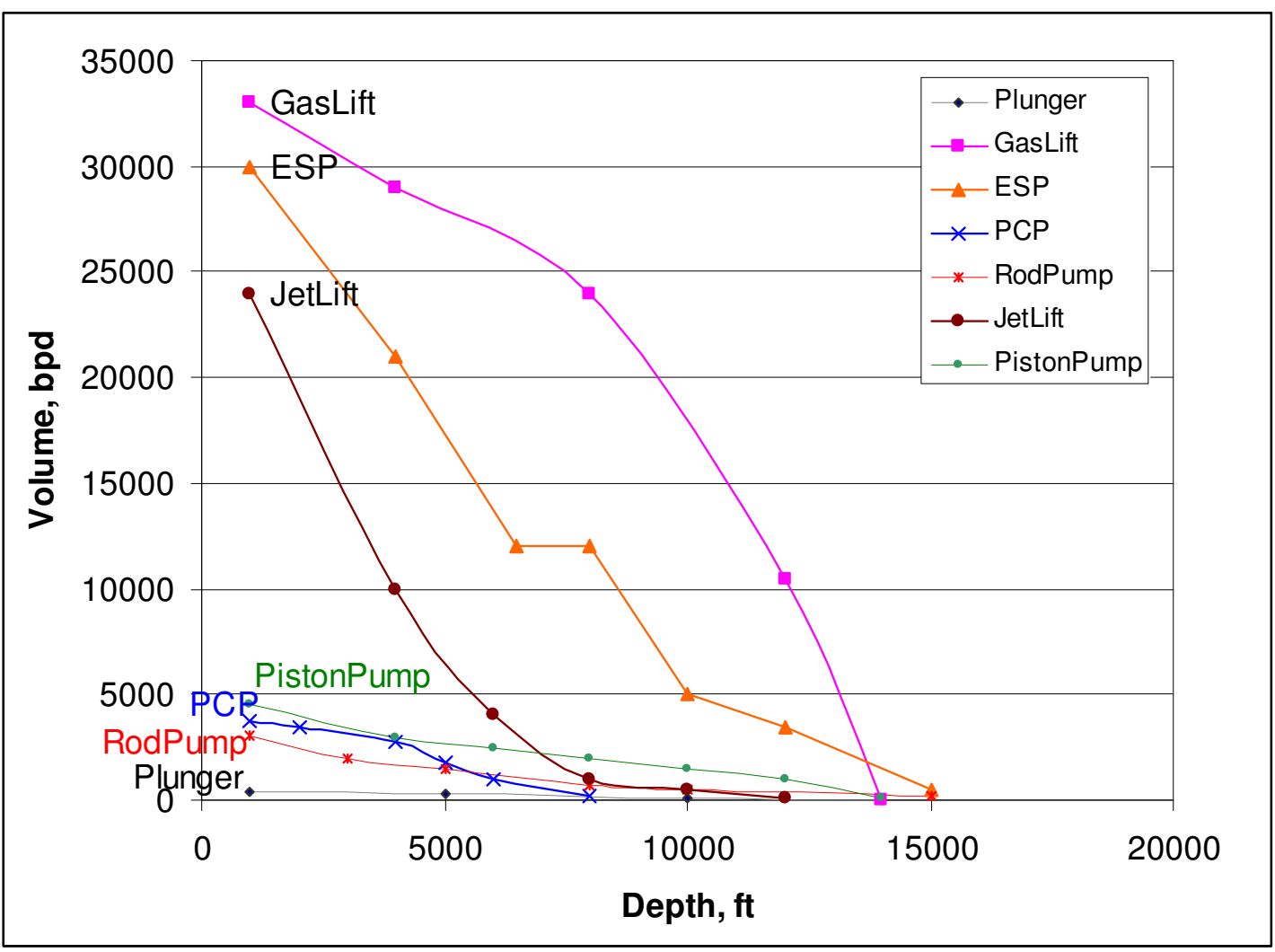

Fig. 4.7 - Approximate depth-rate application chart of technical remedial options (After Lea, 2003) 


\subsubsection{Model Node [5]: Gas-Liquid Ratio (GLR)}

In the selection process of artificial lift method, the producing gas-liquid ration (GLR) needs to be considered. In particular, GLR value should be dealt with first when designing lifting mechanisms. From previous studies on the influence of GLR, we have GLR rule of thumb. In general, this rule states that the well must have a GLR of $400 \mathrm{scf} / \mathrm{bbl}$ for every $1000 \mathrm{ft}$ for application of plunger system (Lea, 2003). However, it varies depending on well geometry, reservoir pressure, and resultant casing buildup operating pressure. Fig. 4.8 and Fig. 4.9 show GLR requirement for plunger system application at different plunger configurations, and a much higher GLR is required at the site of packer installed. Weatherford's brochure regarding plunger system and a paper by Morrow et al (2006) suggest 300scf/bbl/1000ft to consider plunger system. Therefore, we are going to take recent opinion, $300 \mathrm{scf} / \mathrm{bbl} / 1000 \mathrm{ft}$, in this model of the decision matrix.
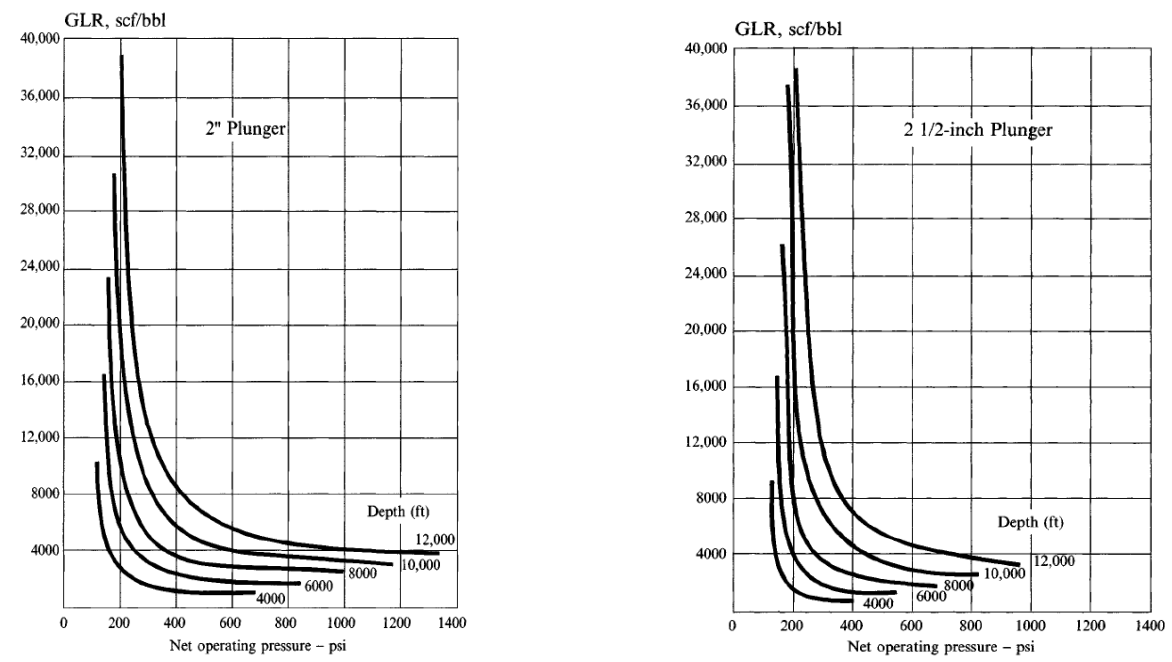

Fig. 4.8 - Feasibility of plunger lift for 2 3/8inch Tubing (Left), 2 7/8inch Tubing (Right) (Beeson et al, 1957) 


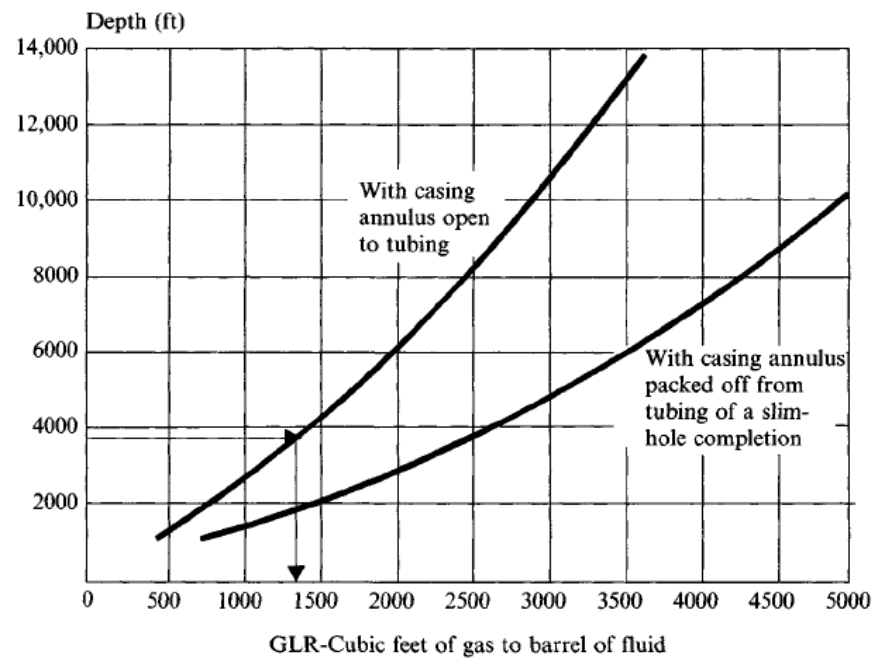

Fig. 4.9 - GLR requirement for plunger lift with/without packer (Otis plunger lift manual, 1991)

Pumping systems such as ESP and PCP need certain gas ratios in fluid to be operated effectively. Most pumping systems become inefficient when the GLR exceeds some high value, typically 500scf/bbl, because of gas interference (Lea, 2003). High volume of gas inside an electrical pump can cause gas interference or severe damage if the ESP installation is not designed properly (Weatherford ESP brochure, 2007).

For foam lift, there is a GLR rule of thumb which says that foam lift can be applied if producing GLR is in a range 428 770scf/bbl/1000ft $(250 \sim 450 \mathrm{~m} 3 / \mathrm{m} 3 / 1000 \mathrm{~m})$ (Solesa et al, 2006). 


\subsubsection{Model Node [6]: Fluid Gravity ( $\left.{ }^{\circ} \mathrm{API}\right)$}

Fluid gravity is one of the most important factors considered when we choose appropriate artificial method. In general, viscosities less than $10 \mathrm{cp}$ (above $30^{\circ} \mathrm{API}$ ) are not a factor in determining the lift method.

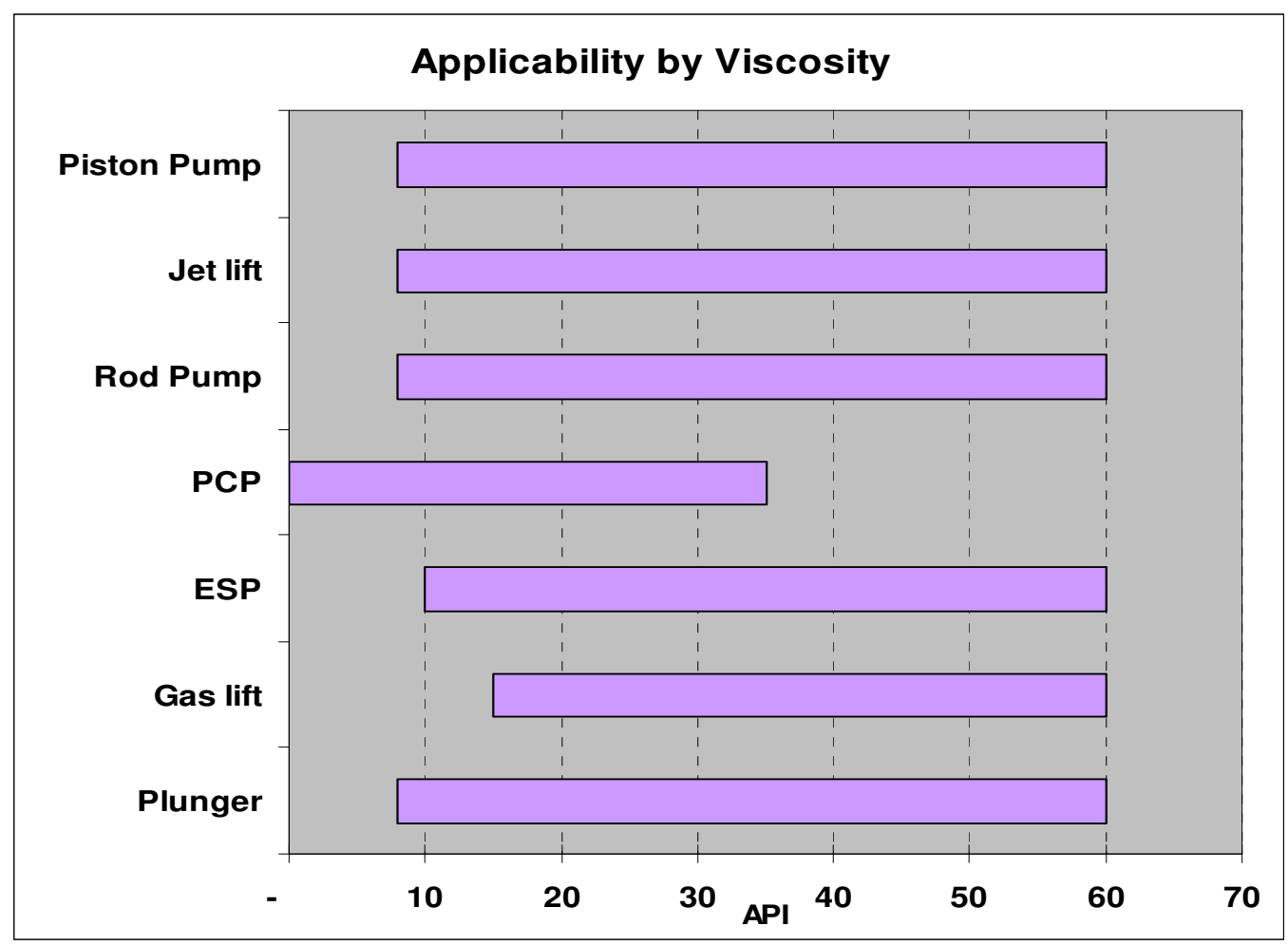

Fig. 4.10 - Technical remedial options' applicability by fluid gravity ( $\left.{ }^{\circ} \mathrm{API}\right)$ (After Weatherford (2007) and Clegg et al (1993))

We need to be cautious for high viscous fluid below $10^{\circ} \mathrm{API}$ because high viscosity fluid is difficult to lift by any method. For Gas lift, high viscous fluids may cause additional problems due to the cooling effect of the gas expanding - a more limited range of fluid gravity that can be operated by other methods. 


\subsubsection{Model Node [7]: Fluid Property (Sand Containment)}

Production with sand causes erosion problems for all types of artificial lift methods. In particular, ESP system is quite open to trouble, while PCP is able to control sand and is regarded as the best sand handling method of all the methods. Several papers explain what solution is given to resolve the problems occurred due to sand while ESP operation. In terms of solutions, use of a downhole desander, use of sand separating device, or installation of ESPCP configured with PCP' advantage are suggested.

\subsubsection{Model Node [8]: Power Availability}

The power availability is critical to the selection of artificial lift method, as it determines if power can be supplied economically.

Table 4.1 - Power Source of Artificial Lift Methods

\begin{tabular}{|l|l|}
\hline & \\
\hline Plunger & Natural energy of well \\
\hline Gas lift & Pressurized gas (Compressor w/ electric motor or gas engine) \\
\hline ESP & Electric motor \\
\hline PCP & Gas engine or Electric motor \\
\hline Rod Pump & Gas engine or Electric motor \\
\hline Jet lift & Multi-cylinder hydraulic pump w/ electric motor or gas engine \\
\hline Piston pump & Multi-cylinder hydraulic pump w/ electric motor or gas engine \\
\hline
\end{tabular}


Low cost power availability is important to project profitability. The table above shows each method's power sources required for operation.

\subsubsection{Result of Round 1}

If we follow all steps of tree with selected options at starting node, the remaining options will be one or two, and in some cases, more than two. From this decision tree, as we remove the remedial options that are impossible to apply at given conditions, we are supposed to obtain the lifting options technically applicable to the given conditions. However, we still wonder what option is the best technically and what profit the option can bring to the project.

Therefore, we need to proceed to Round 2 and 3 in order to rank the methods technically and economically, enabling us to find the most appropriate lifting option at given wells. 


\subsection{Technical Evaluation of Lifting Options [Round 2]}

During the Round 1, we screened preliminary unavailable options. From Round 2, we are going to examine further the screened options in terms of technical aspects and evaluate them so as to rank them. The options have different efficiencies depending on a well's characteristics, such as location and depth. In this sense, the efficiency of each option depending on a well's characteristics and its technical constraints were investigated. With the obtained information, we were able to make technical evaluation matrix like Table 4.2 below. To present each option's efficiency and workability, we used a grading system of 5 different levels of workability (e.g. excellent, good, fair, poor, and limited).

Table 4.2 - Technical Evaluation Matrix

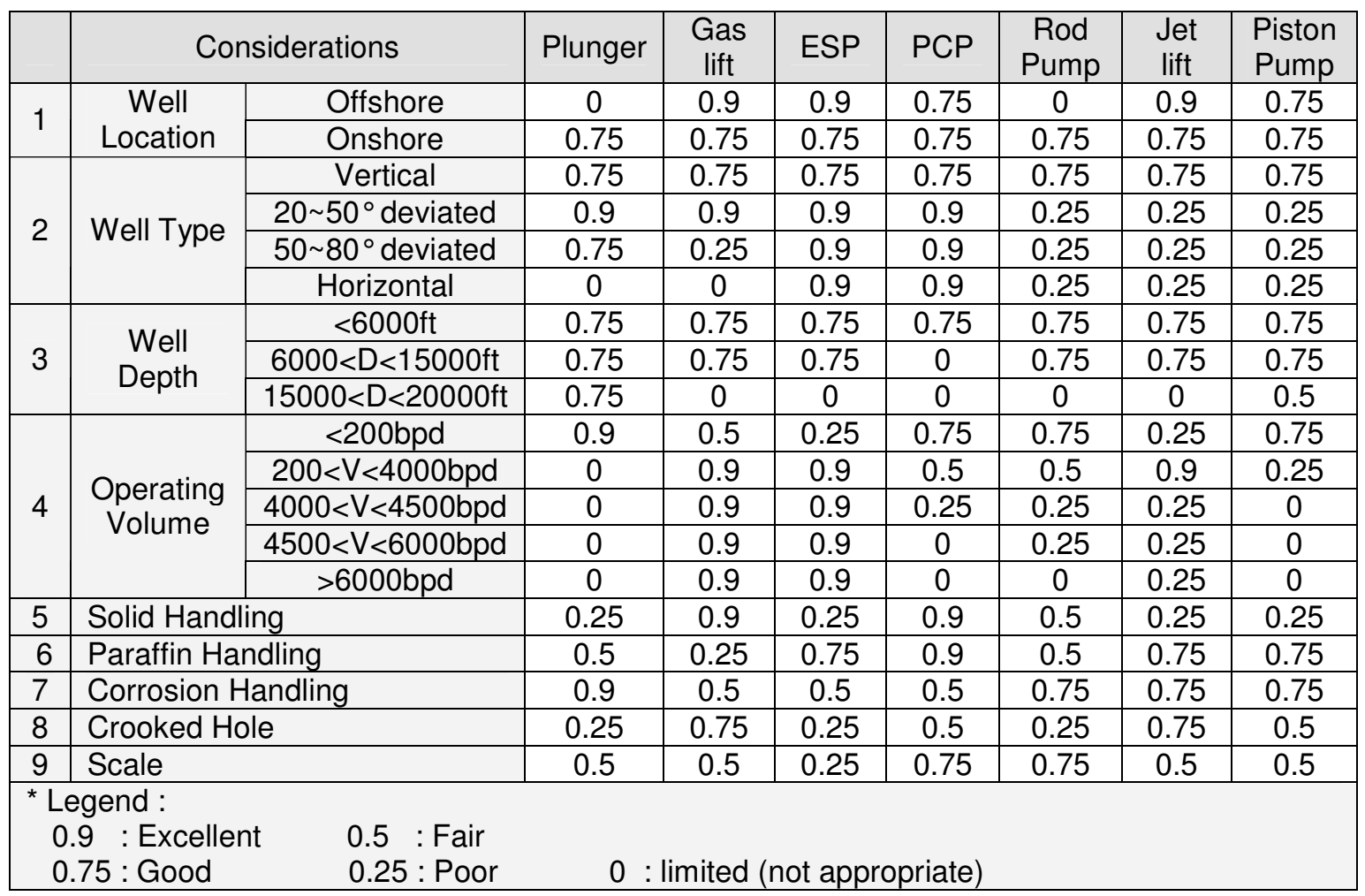


How has each system been evaluated and graded? Basically, we used the technical information obtained from published papers, technical brochures, and reports. In other words, the matrix has been built to fit our specific needs using discovered technical data. In this matrix, we used 9 consideration factors. Among them, 4 factors (well location, well type, well depth, and operating volume) were used in Round 1 as for screening not for evaluating. Thus, references regarding those factors - well location through operating volume - can be found in the previous section 4.2.1 through 4.2.4. The other factors are newly introduced for the purpose of technical evaluation, which are common problems affecting lifting options' selection. For the evaluation of those new factors such as solid handling and scale, numbers of papers were referred to in order to make the matrix. The grade on workability and efficiency can be properly changed or modified by the user because this matrix was made generally acceptable instead of representing if the problem is serious or minor. 


\subsection{Economical Evaluation of Lifting Options [Round 3]}

The purpose of Round 3 is to evaluate every option from an economic point of view. The selection of an economical lifting option is important to the project's profitability. The first step in the economic evaluation is to estimate each option's investment cost and then to compare the costs of each option. The cost comparison chart should be one of the most important sources for decision. The investment cost we considered consists of capital cost, maintenance cost, and fuel and power cost. For detail, the capital cost includes equipment and its installation costs. The maintenance cost includes labor cost, supplies, and cost for MTBF (Mean Time Between Failure). Every cost varies depending on market situation. Thus, it is important that the most updated price information be entered as input value to obtain more precise results of economic evaluation.

After cost comparison, we did a cost/benefit analysis to see how much profit will be made based on the incurred cost and expected revenue. The revenue is calculated by the assumption that the selected lifting option will bring much production compared to the production without installing option. Simply, following equation is used for revenue calculation:

Expected revenue

Eq. 4.2 $=[$ Qgas $\mathrm{w} /$ lifting option- Qgas w/o lifting option $] \mathrm{x}$ gas price $\mathrm{x}$ life of well 
The results of cost/benefit analysis include internal rate of return (IRR) and net present value (NPV) which are yardsticks for decision. Mathematically the IRR is defined as any discount rate that results in a net present value of zero in a series of cash flows. The relationship between NPV and IRR is defined in the following equation:

Eq. 4.2

$$
N P V=0=\text { Initial Investment }+\sum_{t=1}^{N} \frac{C_{t}}{(1+I R R)^{t}}
$$

Where, $\mathrm{C}_{\mathrm{t}}$ is cash at time $\mathrm{t}$

IRR stands for internal rate of return

The cost comparison and cost/benefit analysis are useful for making a final decision regarding the selection of lifting options, because the ranking of each option in terms of economic view can be made based on the results. 


\subsection{Decision Matrix Programming}

Using the software VBL, we programmed a decision matrix based on the developed decision algorithm and evaluation matrixes, meaning that all three rounds are combined in one program. Basically, the programming has been made user-friendly so that the selection process can easily be done. For example, check box and drop-down menu options have been used, which enable users to select an answer quickly and then click to move to the next step and so forth.

\subsubsection{Step by Step Guide to Running Decision Matrix}

In the following section, we are going to examine the whole program step by step. First, we need to discuss Round 1 in regards to screening lifting options and it is therefore called "Preliminary Screening". After Round 1, we will move to Round 2 and then Round 3 for evaluating the options technically and economically. Finally, we will go to the final review sheet that summarizes each Round's results and shows the result of the cost/benefit analysis.

\section{Round 1 [Preliminary Screening]}

The programming on Round 1 has been made based on the developed decision tree. The Fig. 4.11 shows the first step of Round 1 where we will meet with three questions about a well's location, type, and depth. We can easily find an answer by clicking the drop-down menu button. Once all questions have been answered, a user can click the command button "STEP 1 > Find Appropriate Options" to obtain appropriate options. 
For example, if the well is in offshore, drilled vertically, and depth is less than $6000 \mathrm{ft}$, we will get 5 lifting options from among 7 lifting options possible, meaning that 2 options have been screened because they are not appropriate for the given conditions.

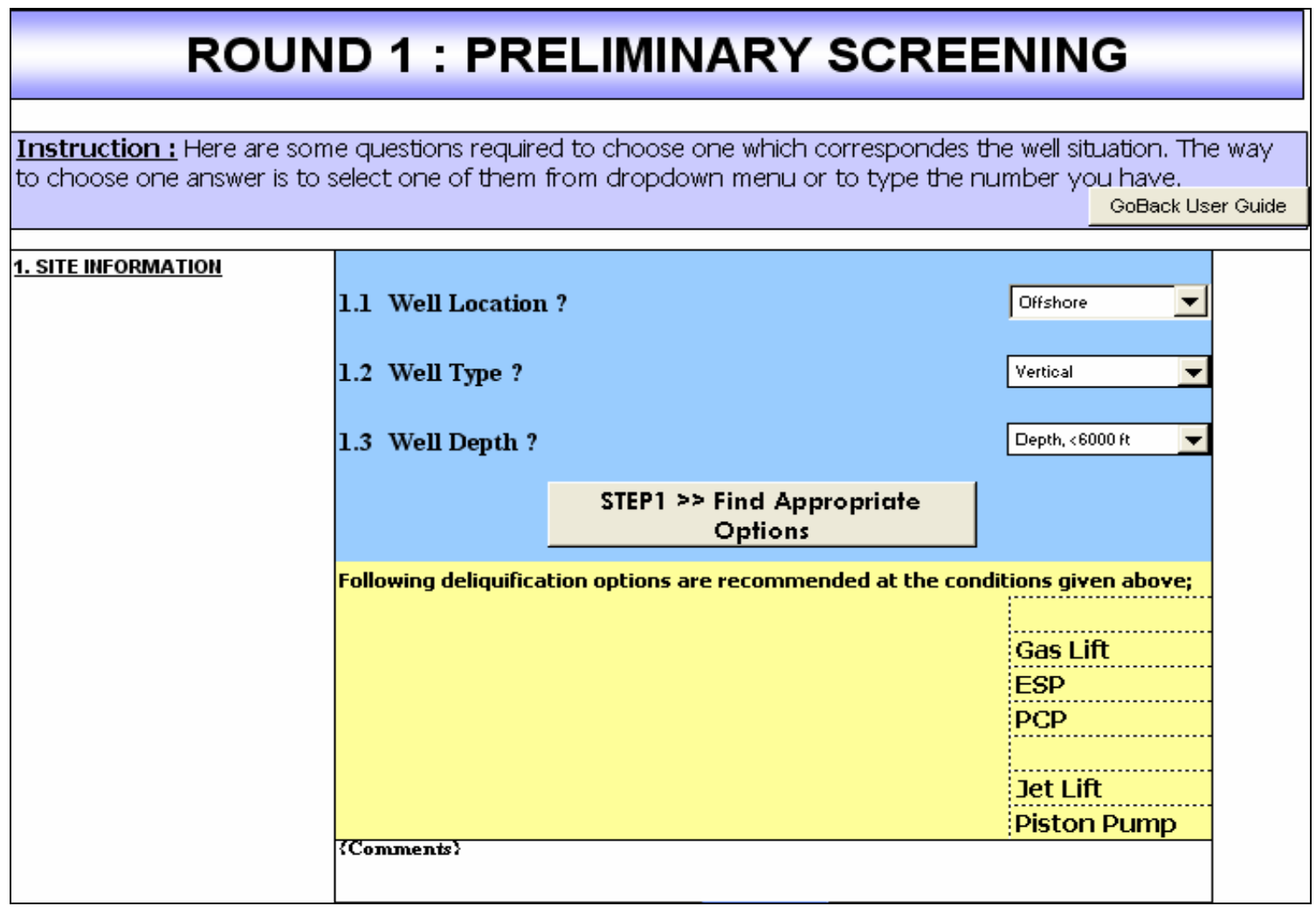

Fig. 4.11 - Programmed decision matrix - Round 1 (1)

Fig. 4.12 represents the second step of Round 1. In this step, we will be asked to answer what operating volume is produced and what GLR value is. Operating volume can be answered by using drop-down menu, but users have to type specific numbers in the cells to answer the GLR value. Then, click the command button "STEP $2>$ Find Appropriate Options" like we did in the step 1, and we can find the options still available. 


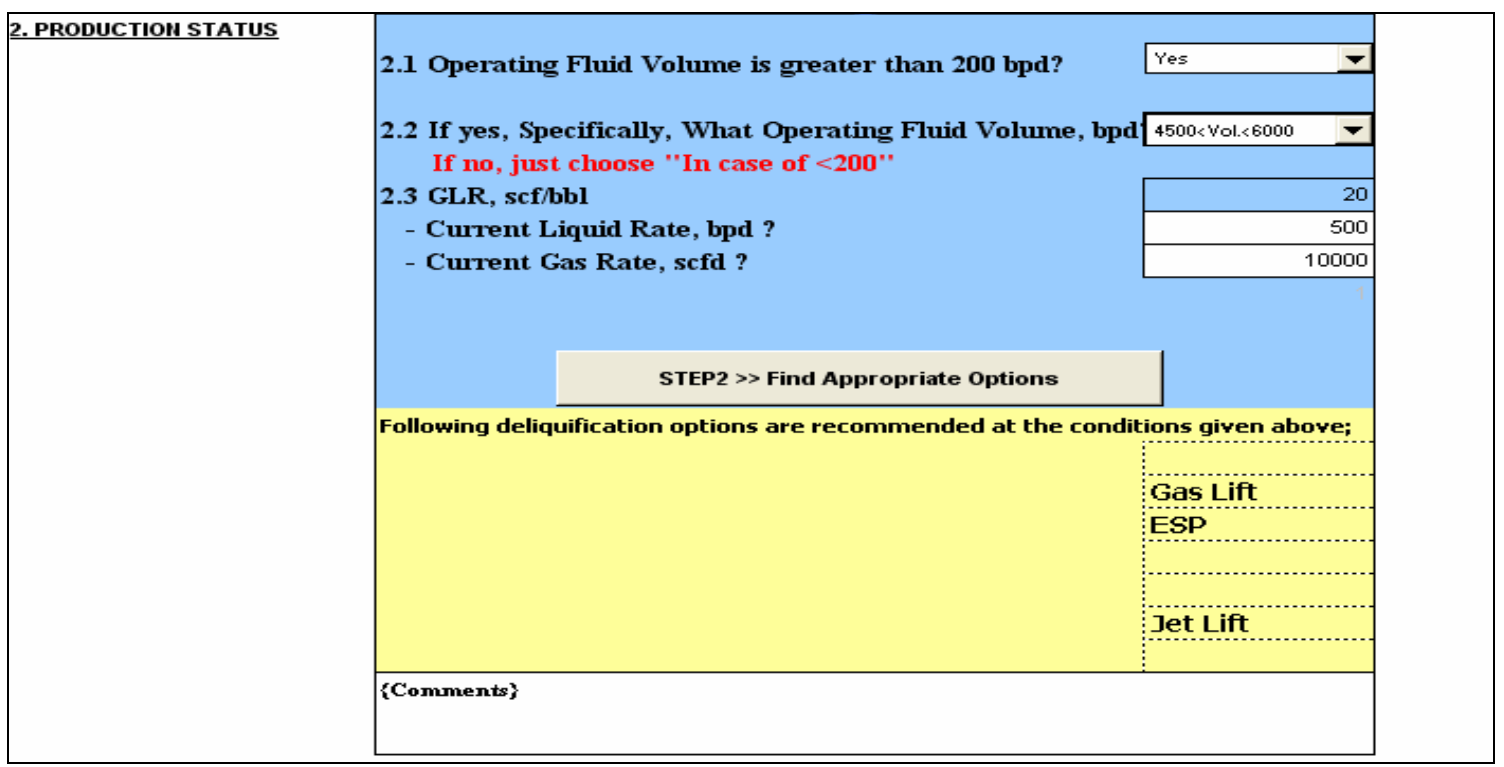

Fig. 4.12 - Programmed decision matrix - Round 1 (2)

The following figure (Fig. 4.13) shows step 3 of Round 1 that checks fluid properties including fluid gravity and sand containment. Choose the answers and click the command button to find appropriate options.

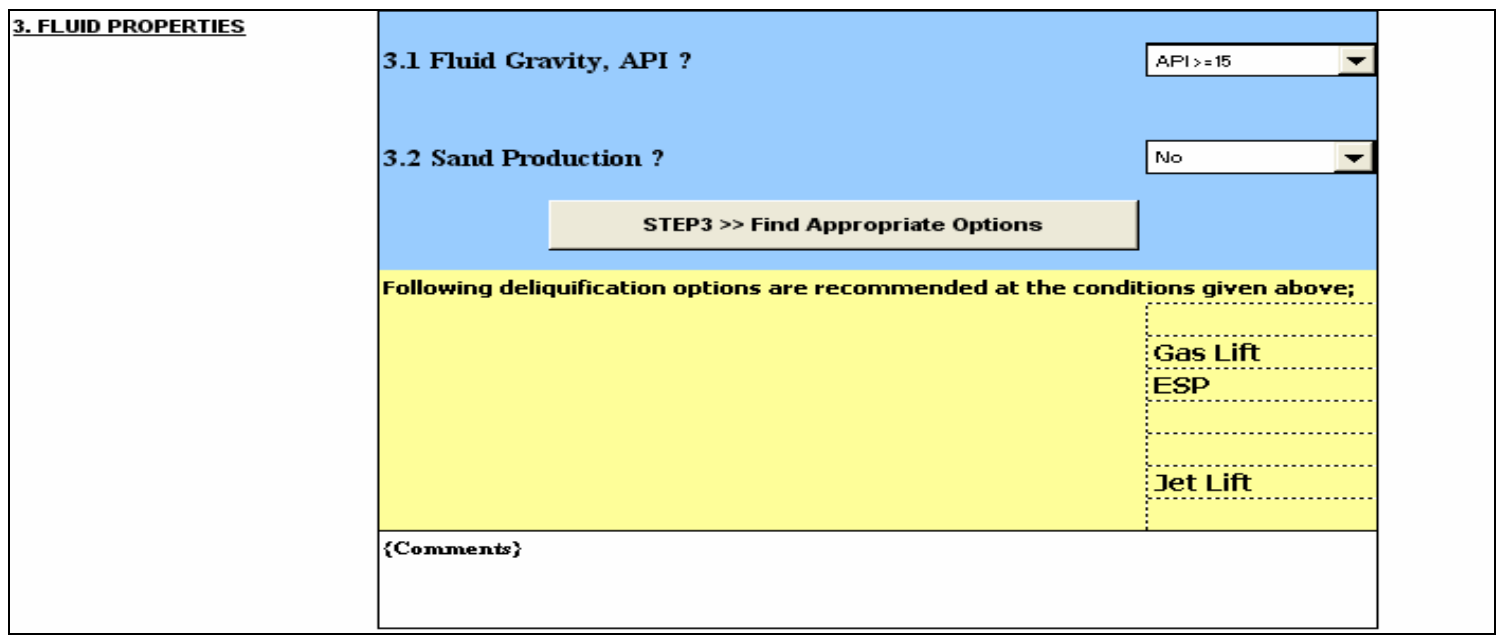

Fig. 4.13 - Programmed decision matrix - Round 1 (3) 
In the last step of Round 1, power availability is checked as seen in Fig. 4.14. After choosing answers from drop-down menu, we finish by clicking the command button.

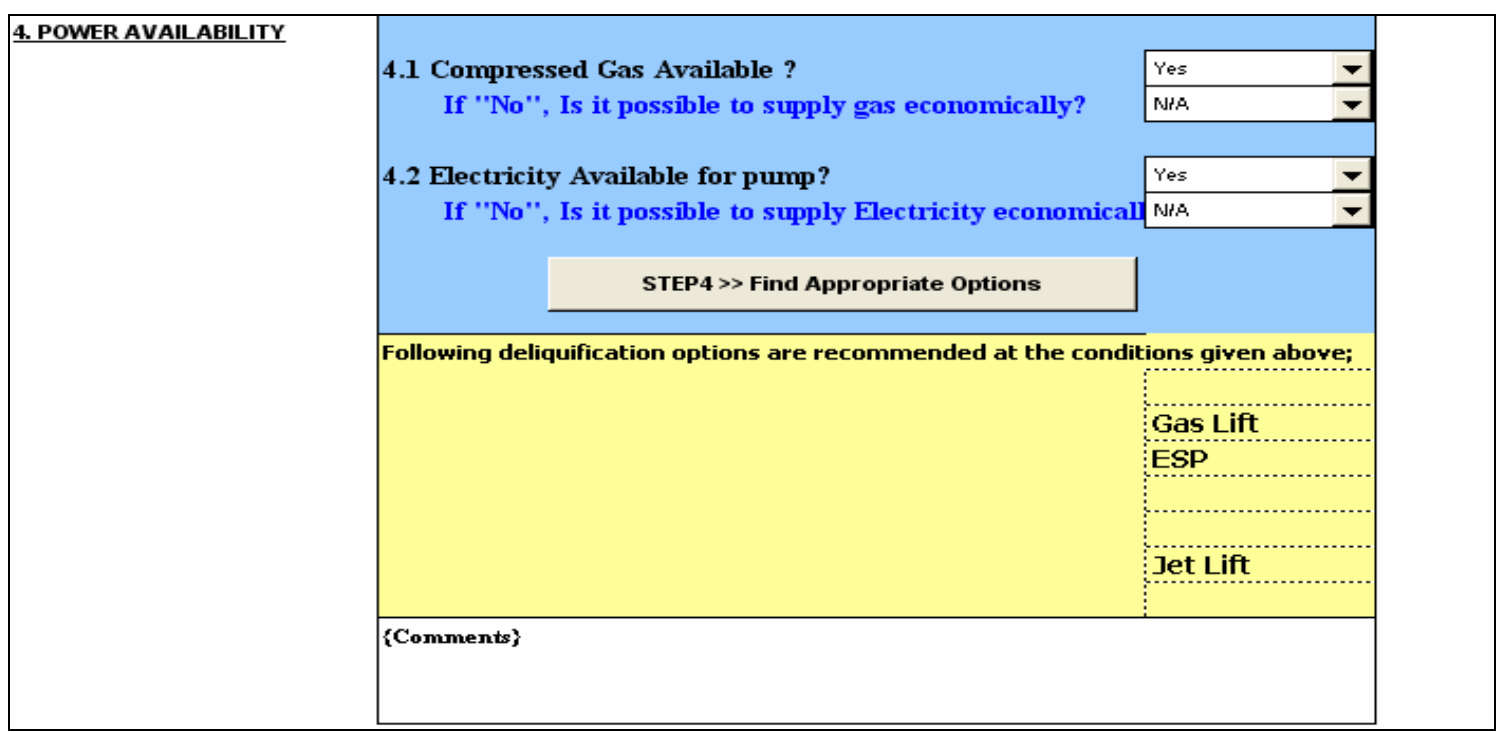

Fig. 4.14 - Programmed decision matrix - Round 1 (4)

Finally, we will see a summary table, like Fig. 4.15, that shows the lifting options that remain from the screening process. For this specific screen process, we find 3 options (Gas lift, ESP, Jet lift) that are appropriate for the given conditions.

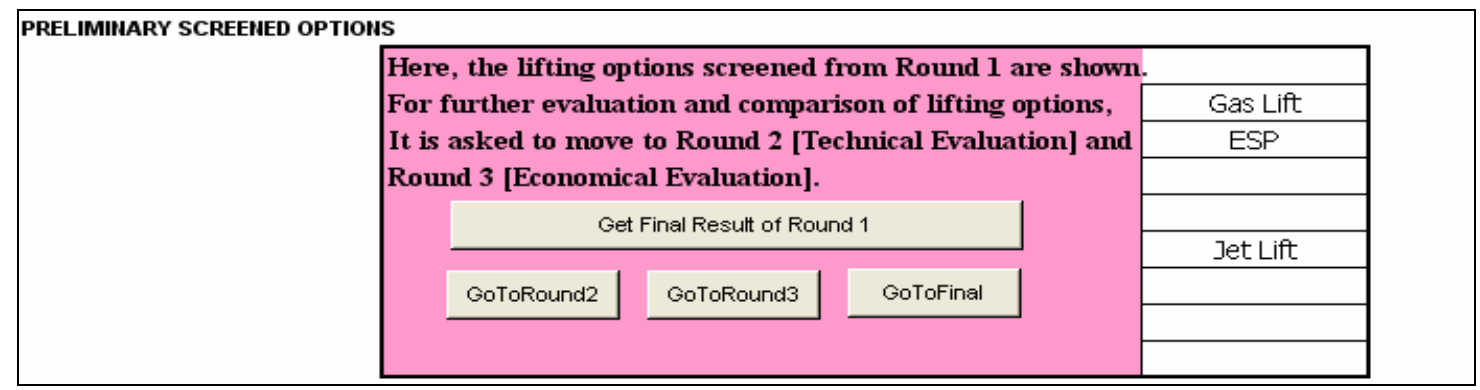

Fig. 4.15 - Programmed decision matrix - Round 1 (5) 


\section{Round 2 [Technical Evaluation]}

Based on the technical evaluation matrix (refer to Table. 4.2), we programmed "Round 2: Technical Evaluation" as shown in Fig. 4.16. As explained before, we are going to evaluate the screened options further in terms of technical aspects. The instruction and screen shot of this Round 2 are given as follows:

○ First, click the command button "Import Screened From R1" to bring the results from Round 1; and

○ Second, answer all items by using drop-down menu.

\section{ROUND 2 : TECHNICAL EVALUATION}

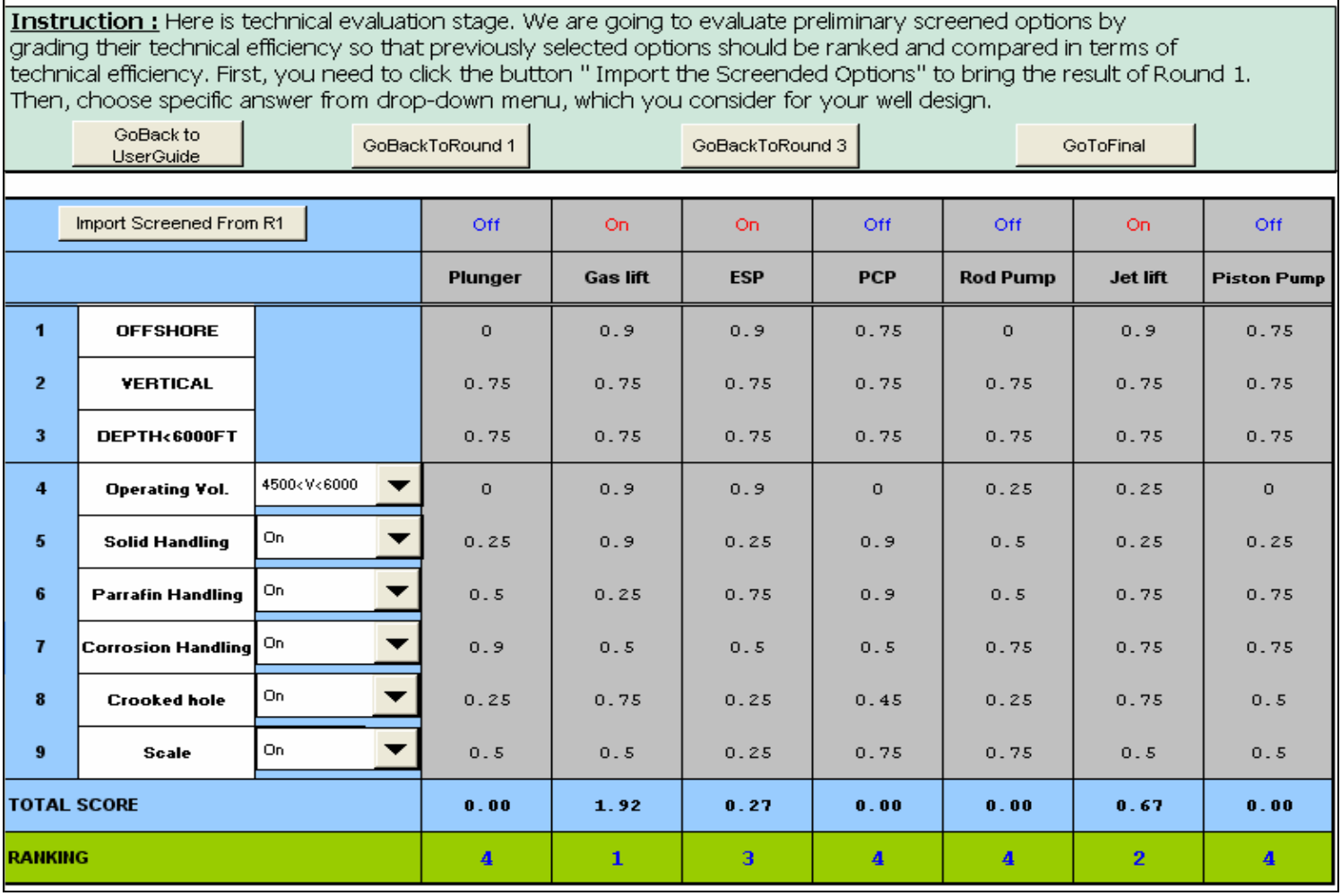

Fig. 4.16 - Programmed decision matrix - Round 2 (1) 
The results can also be found in the graph as exhibited in Fig. 4.16. The gas lift system is the most appropriate in this evaluation stage, but a jet lift system can be considered a close second.

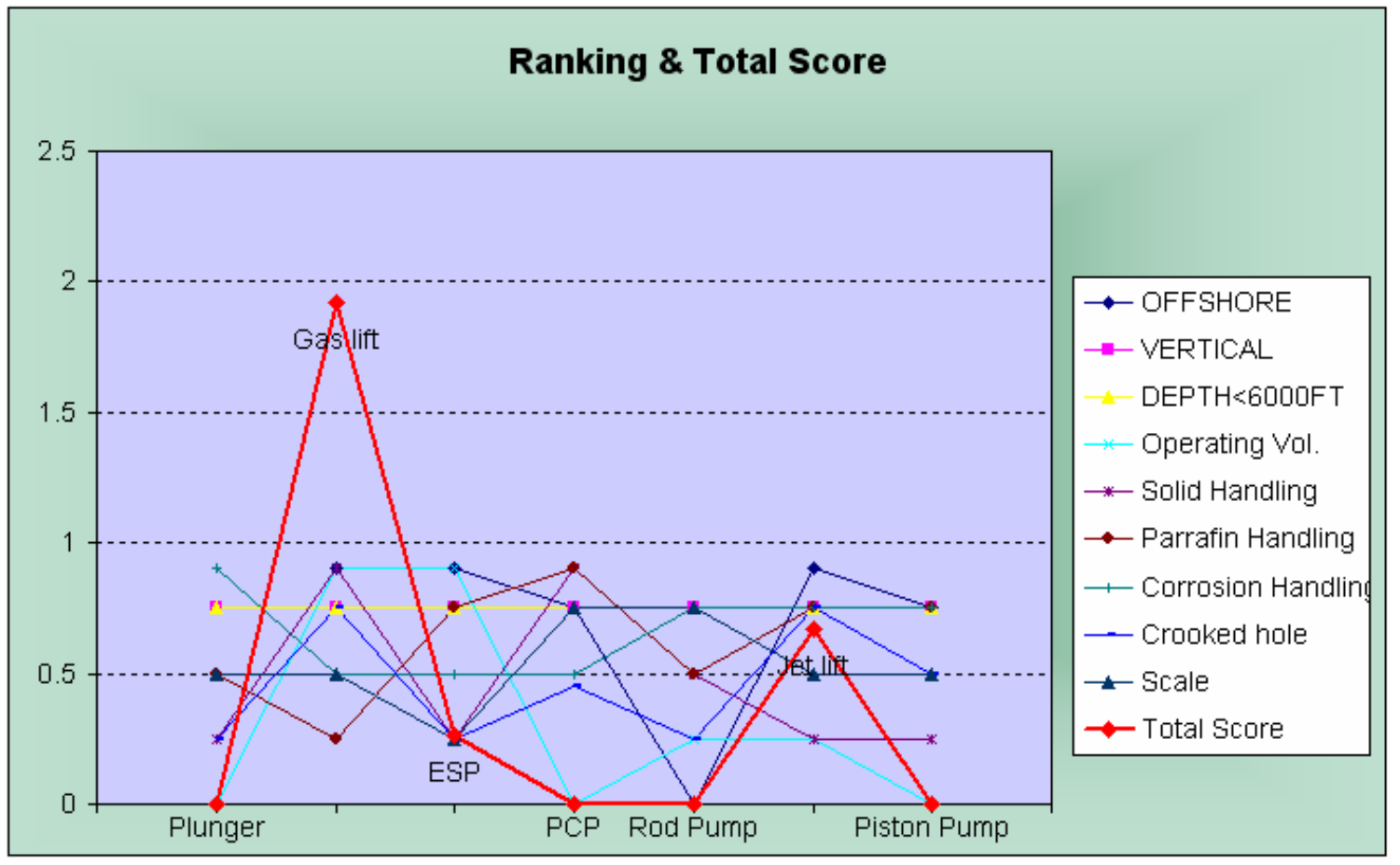

Fig. 4.17 - Programmed decision matrix - Round 2 (2)

\section{Round 3 [Economical Evaluation]}

The purpose of Round 3 is to estimate how much capital cost and maintenance cost will be incurred in order to evaluate each option's economic. The programming has been made based on the economic data set equipped in the program. The economic data is subject to variation; for example, the equipment cost may go up and labor cost also 
icrease. Due to this possibility, it is recommended that the data should be updated regularly.

The main screen of Round 3 is shown below in Fig. 4.17. The first step is to enter the data (e.g. life of well, power cost) into the yellow-colored cells. Then, click the button "Cost Comparison" to see the cumulative cost and cost per well and so on. The chart in the right side of the screen is helpful for comparing the results of each option. As seen in the chart, the gas lift has been presented as the most expensive system for the given conditions.

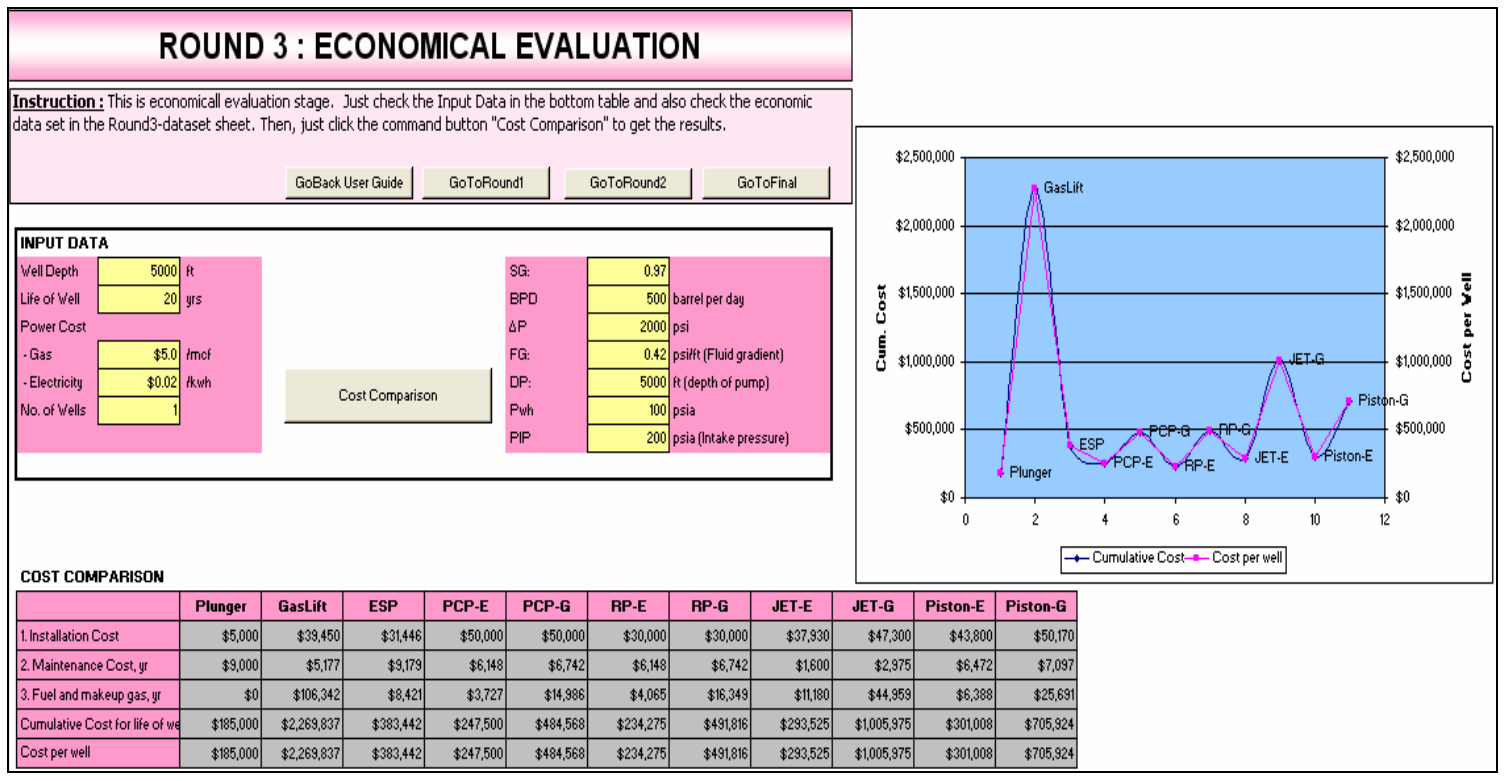

Fig. 4.18 - Programmed decision matrix - Round 3

\section{Comprehensive Review}

This comprehensive review is for reviewing every Round's results and is also for summarizing the results in a screen. In addition, the cost/benefit analysis is given in this 
comprehensive review round. Both Fig. 4.18 and Fig. 4.19 show the results of Round 1 through Round 3. To import the results from each Round, click the command buttons “Import ROUND 1 RESULT", “Import ROUND 2 RESULT”, and "Import ROUND 3 RESULT". Then, we can find the summary of each Round' results.

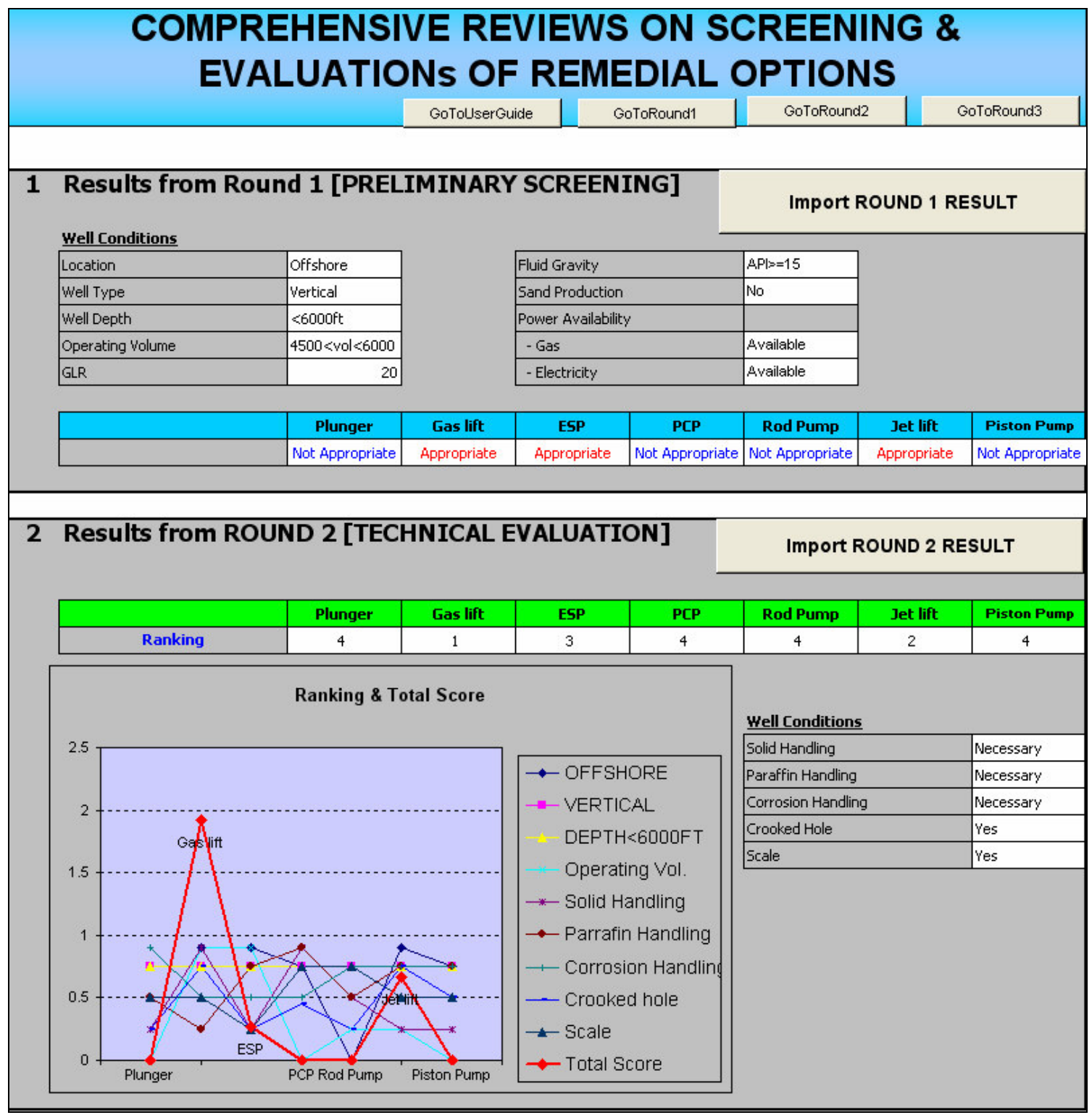

Fig. 4.19 - Programmed decision matrix - Comprehensive review (1) 


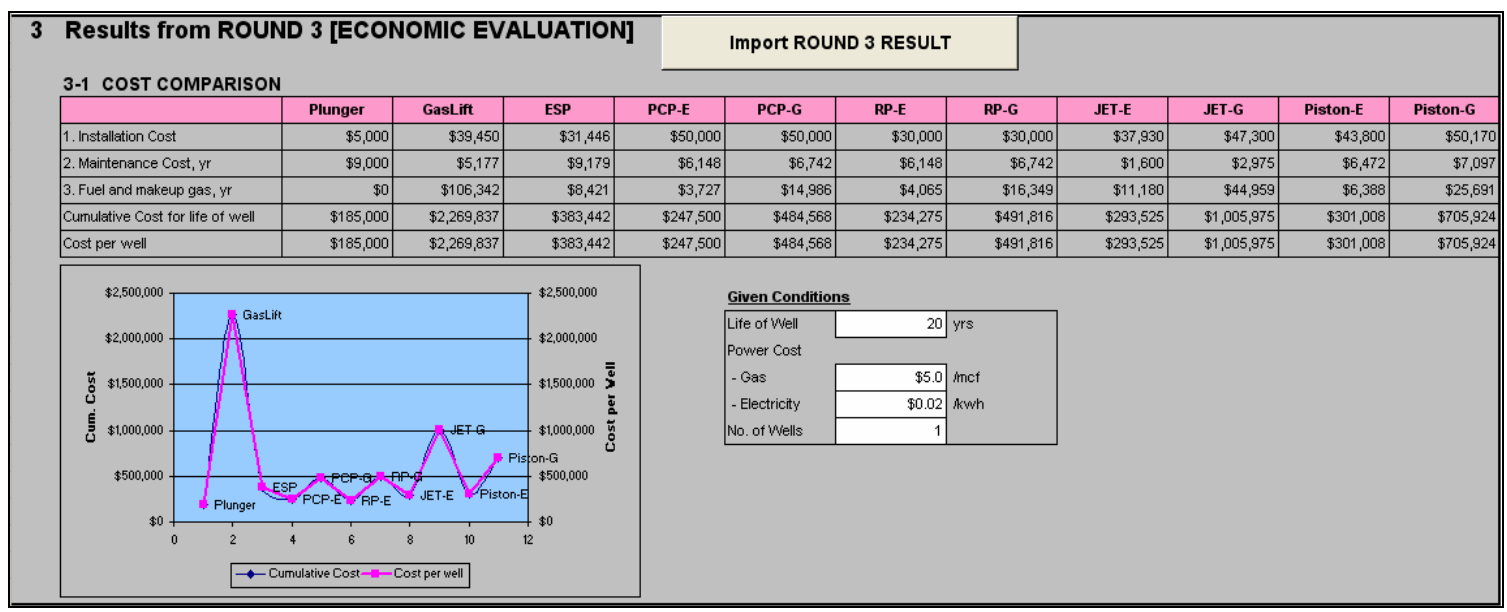

Fig. 4.20 - Programmed decision matrix - Comprehensive review (2)

Finally, the cost/benefit analysis is presented as shown in Fig. 4.20. This analysis aims to provide how much benefit can be incurred when we choose an option. For this analysis, we need to enter the increased production value that can be assumed or estimated by using specific simulation software. Clicking the button "Analysis" allows the users to find each option' net cash flow, IRR, and so on. Moreover, a chart showing each option's NPV (at discount rate 10\%) and IRR is given at the bottom, where we can easily find the most profitable option. 


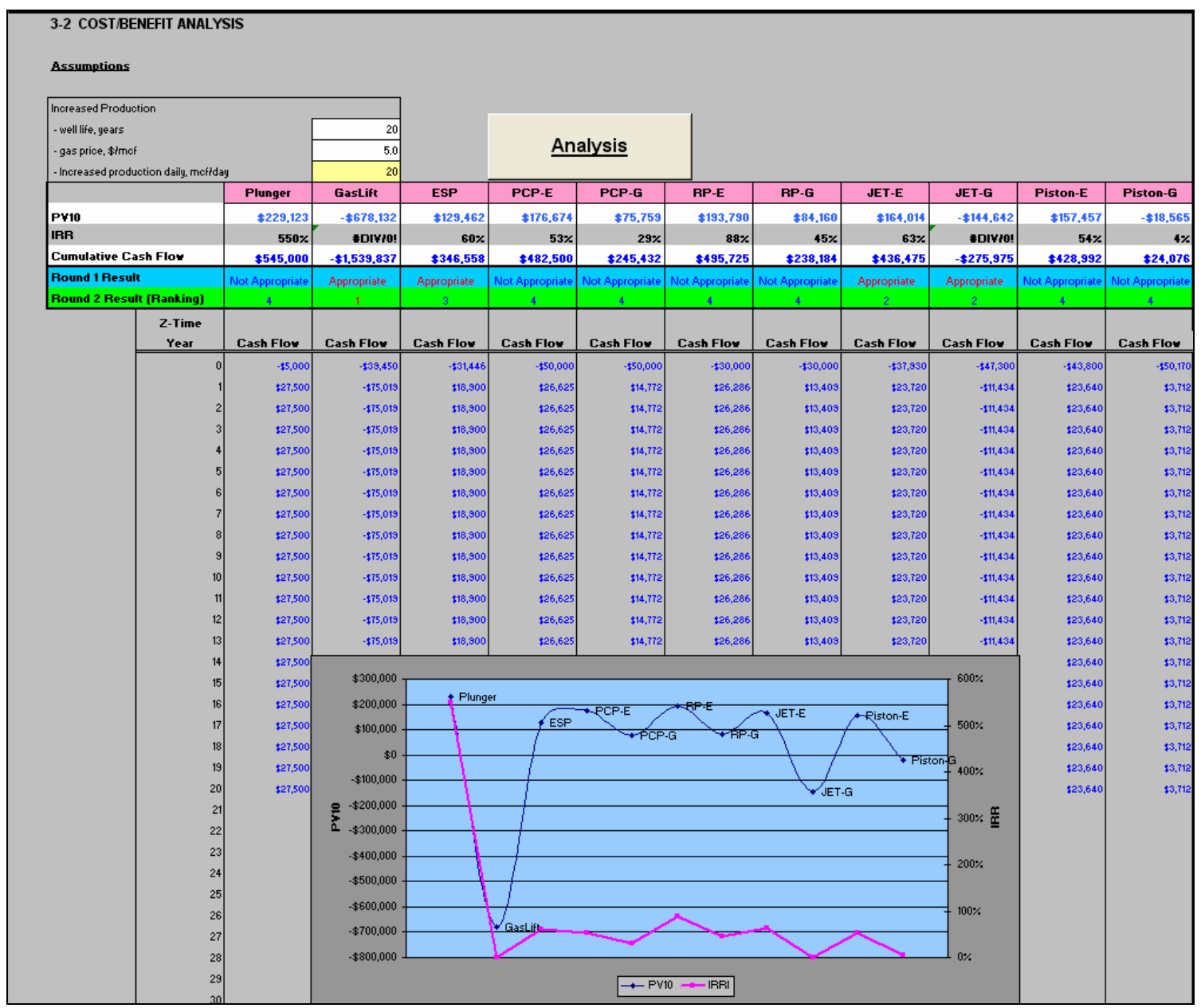

Fig. 4.21 - Programmed decision matrix - Comprehensive review (3) 


\subsection{Field Data to Validate Decision Matrix}

For a better decision tree and better decision matrix, more experience data from actual field operation is still important. The data required for this work will include field data and theoretic data for technical and economical characteristics of each remedial option. The field data required for building such matrix includes, but is not limited to:

○ Field location (onshore or offshore)

○ Field export route (standalone or shared flowlines)

- Field size (in-place and current estimate of recoverable reserves) to serve as a base case profile

- Wellhead/bottomhole pressure and temperature conditions

- Corresponding flow rate

- PVT data

○ Completions details

- Characteristics of the production system (choke valve, manifold, flowlines, risers, separator, etc.)

○ Production logging data

- Existing well and field models (where available and applicable)

○ Cost of each remedial technique (including a comparison between retrofitting costs and pre-installation costs)

More data would bring better results. Thus, the experience data from fields is highly important to do the database work. Without real field data, this project can be based on published documents only with risk of generalizing too much. During this research 
presented in this thesis, several attempts were made to obtain relevant field data from the sponsors of this project. Unfortunately, the attempts were not successful. The lack of field data information to test and validate the decision matrix has inevitably limited the potential of this work. On the other hand, the matrix has been written in such a way that it is fully flexible and users can easily add or modify the selection conditions to satisfy specific field requirements. 


\section{CHAPTER V}

\section{CONCLUSION AND RECOMMENDATION FOR FUTURE WORK}

\subsection{Conclusion}

The work described in this thesis focuses on the development of decision matrix for liquid loading in gas wells for cost/benefit analysis of lifting options. The following conclusions are presented on the basis of this work:

- The data mining technique, specifically a decision tree method, has been used to build a generic decision matrix that is necessary around the industry to select the most appropriate option against the liquid loading problem in gas wells. The developed decision tree (Fig. 4.3) allows for quickly subdividing large initial datasets into successively smaller sets by a series of decision rules. The rules are based on information available in the public domain.

○ A technical evaluation matrix, developed for comparing each option's efficiency in relation to technical consideration factors affecting the selection of a remedial option, helps us to rank the options and therefore easily find the best option.

- In addition to a technical evaluation matrix, an economic evaluation matrix was developed for estimating each option's cost/benefit. This matrix enables us to check its profitability and then choose the most optimum option.

○ The decision matrix has been programmed with VBL by using a newly developed decision tree and evaluation matrixes, and has been proven successful with synthetic data. It is now ready to be tested with real field datasets. 


\subsection{Recommendation for Future Work}

The following main recommendations are made with respect to future work in the area of the development of decision matrix for selection of remedial option against liquid loading problem in gas wells.

○ Test and validate against real field information. In particular, a new field development case would be ideal to test the screening capabilities of the decision matrix.

- Continue to update the decision matrix not only with more remedial options including newly developed techniques but also update with more consideration factors affecting selection of the options which may have been overlooked with this project.

○ Try and implement the decision tree developed under the present work into a more advanced data mining technique. 


\section{NOMENCLATURE}

$\mathrm{P}_{\mathrm{cf}}$ : Casing Flowing Pressure

$\mathrm{P}_{\mathrm{tf}}$ : Tubing Flowing Pressure

Scf : Standard Cubic Feet

bbl : Barrels

bpd : Barrels Per Day

API : American Petroleum Institute

$\prod$ : Capital Pi Notation

Qgas : Production Rate of Gas

w/ : With

w/o : Without

IRR : Internal Rate of Return

NPV : Net Present Value 


\section{REFERENCES}

Artificial Lift Brochures (Plunger lift, Gas lift, ESP, PCP, Sucker rod pump, Hydraulic pumps). Weatherford.

http://www.weatherford.com/weatherford/groups/public/documents/production/prod uction.hcsp\#. Downloaded June 2007.

Beauregard, E. and Ferguson, P.L. 1982. Introduction to Plunger Lift: Applications, Advantages and Limitations. Paper SPE 10882 presented at the Rocky Mountain Regional Meeting of the Society of Petroleum Engineers, Billings, Montana, 19-21 May.

Berry, M.A. and Linoff, G.S. 2004. Data Mining Techniques, Indianapolis, Indiana: Wiley Publishing Inc.

Brown, K.E. 1980. The Technology of Artificial Lift Methods, Tulsa, Oklahoma: The Petroleum Publishing Company.

Clegg, J.D., Bucaram, N.W., and Heln, N.W. J.D. Recommendations and Comparison for Selecting Artificial-Lift Methods. JPT. (December 1993) 1128-1131, 11631167; Trans., Paper SPE 24834.

Dousi, N., Veeken, C.A.M., and Currie, P.K. Modeling the Gas Well Liquid Loading Process. Paper SPE 95282 presented at the Offshore Europe 2005, Aberdeen, Scotland, U.K., 6-9 September.

Hartley, F. Modular Downhole Safety System. www.offshoremag.com/articles_display.cfm. Downloaded 10 September 2007.

Heinze, L.R., Winkler, H.W., and Lea, J.F. 1995. Decision Tree for Selection of Artificial Lift Method. Paper SPE 29510 presented at the Production Operations Symposium, Oklahoma City, Oklahoma, 2-4 April.

Installing Plunger Lift Systems in Gas Wells. EPA. http://www.epa.gov/gasstar/pdf/lessons/l1_plungerlift.pdf. Downloaded March 2007.

Introduction to Data Mining and Knowledge Discovery, third edition. Two Crows, www.twocrows.com. Downloaded 10 February 2007.

Introduction to Plunger Lift. Multi Plungerlift, Presented at Texas A\&M University, College Station, Texas, 26 April 2007. 
Lea, J.F., Bearden, J.L. ESP's: On and Offshore Problems and Solutions. Paper SPE 52159 presented at the 1999 SPE Mid-Continent Operations Symposium, Oklahoma City, Oklahoma, 28-31 March.

Lea, J., Nickens, H., and Wells, M. 2003. Gas Well Deliquification, Burlington, Massachusetts: Gulf Professional Publishing.

Mirza, K.M. 1997. The Progressing Cavity Pump: A Cost-Effective Multiphase Transfer Solution. Paper SPE 39078 presented at the Fifth Latin American and Caribbean Petroleum Engineering Conference and Exhibition, Rio de Janeiro, Brazil, 30 August - 3 September.

Morrow, S.J., Hearn, W., and Cisneros, R. New Techniques for Plunger Lift in Conventional and Nonconventional Gas. Paper SPE 104556 presented at the 2006 SPE Eastern Regional Meeting, Canton, Ohio, 11-13 October.

Patton, L.D. Optimizing Production With Artificial Lift Systems - Part 1 - Basic Types of Lift Systems. Petroleum Engineer International. (July 1989) 30-36.

Patton, L.D. Optimizing Production With Artificial Lift Systems - Part 2 - How to Lower Operating Costs. Petroleum Engineer International. (October 1989) 26-30.

Patton, L.D. Optimizing Production With Artificial Lift Systems - Part 3 - Economy of Sucker Rod Pumping. Petroleum Engineer International. (March 1990) 34-36.

Patton, L.D. Optimizing Production With Artificial Lift Systems - Part 4 - Economy of Sucker Rod Pumping, Combination Strings. Petroleum Engineer International. (April 1990) 50-54.

Patton, L.D. Optimizing Production With Artificial Lift Systems - Part 5 - Economy of Sucker Rod Pumping, Combination Versus All-steel Strings. Petroleum Engineer International. (May1990) 47-48.

Piers, K.D. 2007. Shallow Gas Wells - Technology to Lift Liquids. Presented at the Shallow Gas Production Technology Forum. Calgary, Alberta. March 29, 2007.

Saveth, K.J. and Klein, S.T. 1989. The Progressing Cavity Pump: Principle and Capabilities. Paper SPE 18873 presented at the SPE Production Operations Symposium, Oklahoma City, Oklahoma, 13-14 March.

Skillicorn, D.B., McConnell, S.M., and Soong, E.Y. 2003. Handbook of Data Mining Using Matrix Decompositions, School of Computing, Queen's University, Kingston, Canada. 
Solesa, M. et al.. Production Optimization Challenges of Gas Wells With Liquid Loading Problem Using Foaming Agents. Paper SPE 101276 presented at the 2006 SPE Russian Oil and Gas Technical Conference and Exhibition, Moscow, Russia, 36 October.

Solesa, M., Martinez, J.L., Martinez, O.M. Integrated Solution for Managing Liquid Loading Problem in Gas Wells of Burgos Fields. Schlumberger Private Report (2006).

Torus Insert Safety Valve. Caledyne Ltd.. http://www.caledyne.co.uk/Torus_Safety_System.html. Downloaded September 2007.

Veeken, K., Bakker, E., and Dousi, N. Liquid Loading in Gas Wells Symptoms and Cures. Presented at the 2003 SPE Annual Technical Conference and Exhibition, Denver, Colorado, 16-17 June. 


\section{VITA}

Name: $\quad$ Han-Young Park

Address: 413-1 Jungchun, Keumsan, Jinju, Kyungsangnamdo, 663-920

Republic of Korea

Email Address: hanyoung.park@yahoo.com

Education: $\quad$ B.S in Mineral \& Petroleum Engineering, Hanyang University, Seoul,

Korea, 1996

M.S in Petroleum Engineering, Texas A\&M University, College

Station, Texas, U.S.A, 2008

Experience: $\quad$ Korea Gas Corporation, 1996 to 2006

Member: $\quad$ Society of Petroleum Engineers 